\title{
Oxygen Reduction Kinetics of La2-xSrxNiO 4+delta Electrodes for Solid Oxide Fuel Cells
}

Bo Guan

Follow this and additional works at: https://researchrepository.wvu.edu/etd

\section{Recommended Citation}

Guan, Bo, "Oxygen Reduction Kinetics of La2-xSrxNiO 4+delta Electrodes for Solid Oxide Fuel Cells" (2016). Graduate Theses, Dissertations, and Problem Reports. 5718.

https://researchrepository.wvu.edu/etd/5718

This Thesis is protected by copyright and/or related rights. It has been brought to you by the The Research Repository @ WVU with permission from the rights-holder(s). You are free to use this Thesis in any way that is permitted by the copyright and related rights legislation that applies to your use. For other uses you must obtain permission from the rights-holder(s) directly, unless additional rights are indicated by a Creative Commons license in the record and/ or on the work itself. This Thesis has been accepted for inclusion in WVU Graduate Theses, Dissertations, and Problem Reports collection by an authorized administrator of The Research Repository @ WVU. For more information, please contact researchrepository@mail.wvu.edu. 


\title{
Oxygen Reduction Kinetics of $\mathrm{La}_{2-\mathrm{x}} \mathrm{Sr}_{\mathrm{x}} \mathrm{NiO}_{4+\delta}$ Electrodes for Solid Oxide Fuel Cells
}

\author{
Bo Guan \\ Thesis submitted to \\ Benjamin M. Statler College of Engineering and Mineral Resources \\ at West Virginia University \\ in partial fulfillment of the requirements \\ for the degree of \\ Master of Science \\ In \\ Mechanical Engineering
}
Xingbo Liu, Ph.D., Chairperson and Advisor
Xueyan Song, Ph.D.
Hui Zhang, Ph.D.
Department of Mechanical and Aerospace Engineering
Morgantown, West Virginia
2016

Keywords: Surface kinetics, $\mathrm{LaNiO}_{4+\delta}$ cathode, electrochemical impedance spectroscopy

Copyright 2016 Bo Guan 


\section{Abstract \\ Oxygen Reduction Kinetics of $\mathrm{La}_{2-\mathrm{x}} \mathrm{Sr}_{\mathrm{x}} \mathrm{NiO}_{4+\delta}$ Electrodes for Solid Oxide Fuel Cells \\ Bo Guan}

In the development of intermediate temperature solid oxide fuel cell (IT-SOFC), mixed ionic-electronic conductors (MIEC) have drawn big interests due to their both ionic and electronic species transport which can enlarge the 3-dimension of the cathode network. This thesis presents an investigation of MIEC of Ruddlesden-popper (RP) phases like $\mathrm{K}_{2} \mathrm{NiF}_{4}$ type $\mathrm{La}_{2} \mathrm{NiO}_{4+\delta}$ (LNO)-based oxides which have interesting transport, catalytic properties and suitable thermal expansion coefficients. The motivation of this present work is to further understand the fundamental of the effect of $\mathrm{Sr}$ doing on the oxygen reduction reaction (ORR) kinetics of LNO cathode.

Porous symmetrical cells of $\mathrm{La}_{2-\mathrm{x}} \mathrm{Sr}_{\mathrm{x}} \mathrm{NiO}_{4+\delta}(0 \leq \mathrm{x} \leq 0.4)$ were fabricated and characterized by electrochemical impedance spectroscopy (EIS) in different $P_{\mathrm{O} 2}$ from temperature range of $600 \sim 800^{\circ} \mathrm{C}$. The spectra were analyzed based on the impedance model introduced by Adler et al. The rate determining steps (RDS) for ORR were proposed and the responsible reasons were discussed. The overall polarization resistances of doped samples increase with Sr level. Surface oxygen exchange and bulk ionic diffusion cocontrol the ORR kinetics. With high Sr content $(x=0.3,0.4)$, oxygen ion transfer resistance between nickelate/electrolyte is observed.

However for porous symmetrical cells it is hard to associate the resistance from EIS directly to each ORR elementary processes because of the difficulty in describing the microstructure of the porous electrode. The dense electrode configuration was adopted in this thesis. By using the dense electrode, the surface area, the thickness of electrode, the interface between electrode and electrolyte and lastly the 3PB are theoretically well-defined. Through this method, there is a good chance to distinguish the contribution of surface exchange from other processes. Dense and thin electrode layers in thickness of $\sim 40 \mu \mathrm{m}$ are fabricated by using a novel spray modified pressing method. Negligible bulk diffusion resistance is confirmed by parallel experiment and EIS analysis, resulting in exclusive focus on the surface process. It is ambiguously proved that Sr doping impairs the surface kinetics of lanthanum nickelates. The interstitial oxygen is suggested to be the key role when the oxygen incorporation is rat determining. For the first time, a physical model is proposed to illustrate how those interstitial species work to regulate the exchange rate of the incorporation reaction.

To achieve better surface exchange ability on LNO, Mn is chosen as the doping element substituted for $\mathrm{Ni}$ with different levels to improve the surface kinetics because $\mathrm{Mn}$ is much active both for adsorption process and for incorporation process due to the high state of Mn leading to the high amount of the interstitial oxygen. $\mathrm{Mn}$ is found to substantially promote the surface kinetics, showing highest surface exchange coefficient $(k)$ of $1.57 \times 10^{-6} \mathrm{~cm} / \mathrm{s}$ at $700^{\circ} \mathrm{C}$ on composition of $\mathrm{La}_{1.8} \mathrm{Sr}_{0.2} \mathrm{Ni}_{0.9} \mathrm{Mn}_{0.1} \mathrm{O}_{4+\delta}$. Such value is $\sim 80 \%$ larger than that of the undoped sample, and is one of the highest $k$ among the currently available R-P phase intermediate temperature (IT) cathode 


\section{Acknowledgments}

I would like to express my sincere appreciation to my supervisor Dr. Xingbo Liu, for providing me with the opportunity to pursue my Master studying. I am truly grateful for his guidance, understanding, patience, and most importantly, his encouragement during my research. Through him, my mind was opened to wider fields and I become a qualified candidate who can handle critical comments with careful respect.

I would also like to thank the rest of my thesis committee, Dr. Xueyan Song and Dr. Hui Zhang for their mentoring and assistance in experimental and discussions.

I also thank all my group members, Dr. Greg Collins, Meng Yao, Xinxin Zhang, Jianhua Yan, Shanshan Hu, Nan Zhang, He Qi and Jiang Chang, for their assistance in experimental and discussion. I also want to thank Tao Yang for his generous and knowledgeable suggestions. I appreciate that I can get help from all of them and I am very happy we can have a memorable happy time.

Specially thank my husband Wenyuan Li for his support, care, and encouragement during my graduate study and daily life. Thank my parents for their unconditional love. 


\section{TABLE OF CONTENTS}

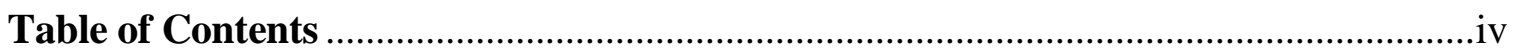

List of Tables .............................................................................................................

List of Abbreviation ................................................................................................ vii

Chapter 1: Introduction and Research Objectives .......................................................... 1

1.1 SOFCs cathode ………………………................................................................

1.2 Ruddlesden-Popper phase cathode...............................................................................

1.3 Dense electrode EIS.............................................................................................

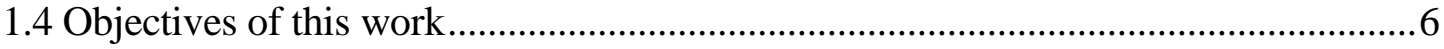

Chapter 2: Experimental methods..............................................................................

2.1 Fabrication cathode materials by Sol-Gel synthesis ......................................................

2.2 Fabrication dense double layers by modified spray -pressed .........................................

2.3 Fabrication symmetrical cells...................................................................................9

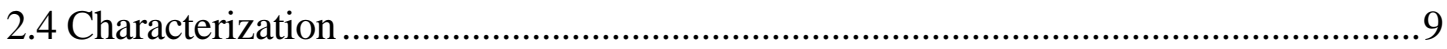

Chapter 3: Investigation of Sr-doped LNO on porous symmetrical cells.......................11

3.1Characterization of basic physic properties of different candidates ............................11

3.2 Decreased performance upon Sr doping and the co-limited electrode process ........13

3.3 Reaction order and surface limiting steps ................................................................21

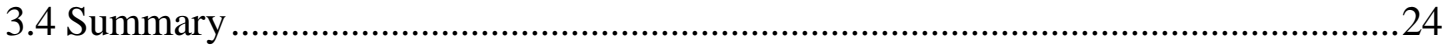

Chapter 4: Investigation of surface exchange kinetics on dense symmetrical cells......25

4.1 Chemical stability with LSGM and microstructure of LSNO thin layers .................26

4.2 Surface-dominant situation on the well-defined R-P cathodes ...................................27

4.3 Surface exchange kinetics of LSNO .........................................................................

4.4 The role of $\mathrm{O}_{\mathrm{i}}$ in the incorporation reaction of R-P phase.........................................36

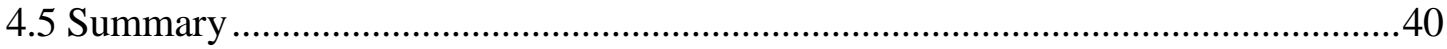

Chapter 5: Improvement of surface kinetics by Mn\&Sr doping ....................................42

5.1 XRD and electrical conductivity of Mn\&Sr doped LNO............................................42

5.2 Surface improvement by Mn doping ........................................................................4

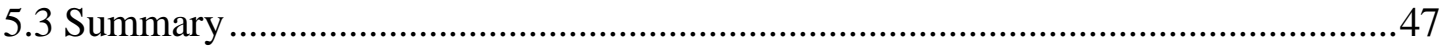

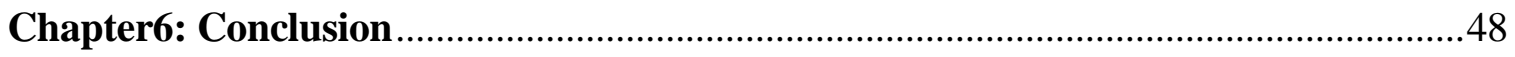




\section{List of Figures}

Figure 1.1 Schematic $\mathrm{ABO}_{3}$ perovskite structure ………………………………….... 2

Figure 1.2 Schematic $\mathrm{AA}^{\prime} \mathrm{B}_{2} \mathrm{O}_{5+\mathrm{x}}$ double perovskite structure …….................................... 4

Figure 1.3 Schematic $\mathrm{A}_{2} \mathrm{BO}_{4+\mathrm{x}} \mathrm{RP}$ phase structure.......................................................... 5

Figure 3.1 patterns for $\mathrm{La}_{2-\mathrm{x}} \mathrm{Sr}_{\mathrm{x}} \mathrm{NiO}_{4+\delta} \mathrm{L}(\mathrm{x}=0,0.1,0.2,0.3,0.4)$ samples.............................. 9

Figure 3.2 Electrical conductivities for $\mathrm{La}_{2-\mathrm{x}} \mathrm{Sr}_{\mathrm{x}} \mathrm{NiO}_{4+\delta}$ tested in air ................................. 10

Figure 3.3 Cross-section view of Sr10 electrode …………………………………....... 11

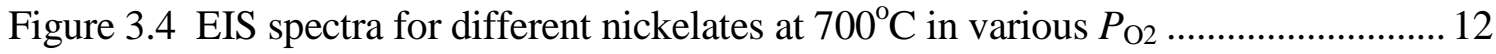

Figure 3.5 Bode plot for Sr30(a), and ALS fitting for LNO(b) and Sr30(c)...................... 13

Figure 3.6 The evolution of chemical capacitance with $P_{\mathrm{O} 2}$ at $700^{\circ} \mathrm{C}$................................ 17

Figure 3.7 Reaction orders from the overall polarization resistances for

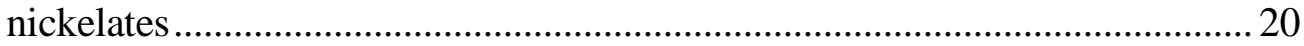

Figure 4.1 XRD for LSNO/LSGM mixtures heated at $1300^{\circ} \mathrm{C}$........................................ 25

Figure 4.2 Cross-sectional SEM for LSNO thin layers ....................................................... 25

Figure 4.3 (a)The equivalent circuit for LSNO dense electrode with electronic rail block by LSGM, (b)EIS profiles simulated by Z-view,

(c) The simplified circuit for the surface-dominant case ..................................... 27

Figure 4.4 (a)Measured and fitted surface-dominant spectrum of LNO

(b)comparison of EIS profiles for LNO, Sr20 and Sr40 ……............................ 29

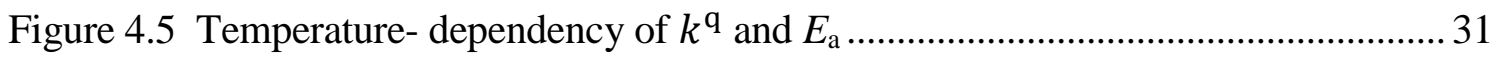

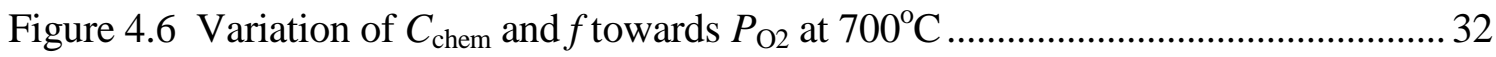

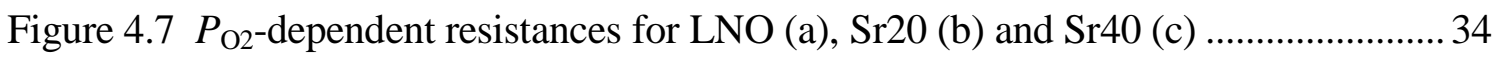

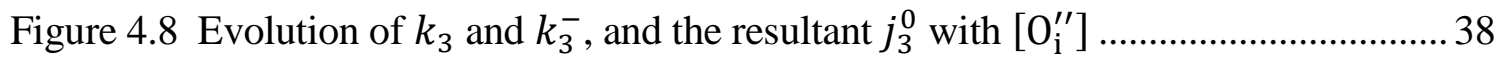

Figure 4.9 Equivalent circuit for LSNO with two subsequent surface processes............... 39

Figure 5.1 (a)XRD of LSNM samples synthesized at different temperatures and mixture of Sr60Mn30 and LSGM calcined at $1300^{\circ} \mathrm{C}$, (b)electrical conductivity of LSNM in air from $100-800^{\circ} \mathrm{C}$.................................................... 42

Figure 5.2 Cross-section of Sr15Mn5/LSGM ................................................................. 44

Figure 5.3 EIS of LSNM symmetrical cells at $700^{\circ} \mathrm{C}$ in air ........................................... 45

Figure 5.4 Equivalent $k$ for LSNM calculated from $R_{\text {surf } \ldots \ldots \ldots \ldots \ldots \ldots \ldots \ldots \ldots \ldots \ldots \ldots \ldots \ldots \ldots \ldots \ldots \ldots \ldots \ldots \ldots . . .} 46$ 


\section{List of Tables}

Table 3-1 Summary of resistances, capacitances, characteristic frequencies

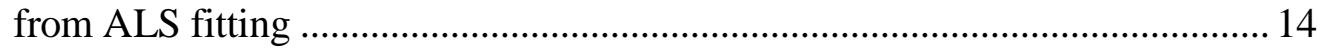

Table 3-2 Estimated characteristic lengths in the bulk .................................................. 16

Table 4-1 Summary of $R_{\text {surf }}$ from different cells measured in air at various temperatures and the related relative standard deviation (RDS) ...................... 26

Table 5-1 Comparison of $k$ for common R-P phase cathodes at $700^{\circ} \mathrm{C}$........................... 47 


\section{List of Abbreviation}

\begin{tabular}{|c|c|}
\hline 3РB & Three-phase boundary \\
\hline $2 \mathrm{~PB}$ & Two-phase boundary \\
\hline ECR & Electrical conductivity relaxation \\
\hline EIS & Electrochemical impedance spectroscopy \\
\hline GDC & $\mathrm{Gd}_{0.2} \mathrm{Ce}_{0.8} \mathrm{O}_{2-\delta}$ \\
\hline LSM & $(\mathrm{LaSr}) \mathrm{MnO}_{3 \pm \delta}$ \\
\hline LSGM & $(\mathrm{LaSr})(\mathrm{GaMg}) \mathrm{O}_{3-\delta}$ \\
\hline LSCF & $(\mathrm{LaSr})(\mathrm{CoFe}) \mathrm{O}_{3}$ \\
\hline LNO & $\mathrm{LaNiO}_{4+\delta}$ \\
\hline LSNO & $\mathrm{La}_{2-\mathrm{x}} \mathrm{Sr}_{\mathrm{x}} \mathrm{NiO}_{4+\delta}$ \\
\hline MIEC & Mixed ion and electron conductor \\
\hline ORR & Oxygen reduction reaction \\
\hline RDS & Rate determining step \\
\hline IT-SOFC & Intermediate temperature solid oxide fuel cell \\
\hline TEC & Thermal expansion coefficient \\
\hline YSZ & Yttrium stabilized zirconia \\
\hline C & Capacitance \\
\hline c & Concentration \\
\hline$D$ & Chemical diffusion coefficient \\
\hline e & Electron change \\
\hline$E_{\mathrm{a}}$ & Activation energy \\
\hline$f_{0}$ & Characteristic frequency \\
\hline$F$ & Faraday constant \\
\hline$k$ & Surface exchange coefficient \\
\hline$k_{\mathrm{B}}$ & Boltzmann constant \\
\hline$n$ & Reaction order \\
\hline $\mathrm{O}_{\mathrm{i}}^{\prime \prime}$ & Interstitial oxygen \\
\hline$P_{\mathrm{O} 2}$ & Oxygen partial pressure \\
\hline$R$ & Reaction rate \\
\hline$R_{\mathrm{p}}$ & Polarization resistance \\
\hline$V_{\mathrm{O}}^{*}$ & Oxygen vacancy \\
\hline$\sigma$ & Conductivity \\
\hline
\end{tabular}




\section{Chapter 1: Introduction and Research Objectives}

As electrochemical devices converting chemical energy of fuel directly into electrical energy, solid oxide fuel cell (SOFC) has been drawing increasing interest because its high energy conversion efficiency. During operation, in the cathode side oxygen from air is flowed as an oxidant and in the anode side hydrogen or hydrocarbons are used as fuel and the solid electrolyte transports $\mathrm{O}^{2-}$ ions from the cathode to anode side. However, the high operating temperature $\sim 1000^{\circ} \mathrm{C}$ leads to undesired reaction and harms the long-term stability. These difficulties lead researchers changing their interests to intermediate temperature (500 $800^{\circ} \mathrm{C}$ ) SOFC (IT-SOFC), and lowering the operation temperature has become one of the main SOFC research goals.[1-3] Nevertheless the lower operating temperature leads to poor oxygen reduction reaction kinetics with the conventional cathode materials, e.g. $\mathrm{La}_{1-\mathrm{x}} \mathrm{Sr}_{\mathrm{x}} \mathrm{MnO}_{3}$ (LSM). In this regard, mixed ionic and electronic conducing (MIEC) materials which have high catalytic activity at lower temperature become potential candidate as cathode electrodes for IT-SOFCs. MIEC are not only active catalysts for surface ORR but also allow substantial interstitial oxygen or vacancy in their bulk which can enlarge the 3-dimension of the cathode network. Recently, one kind of MIEC materials in Ruddlesden-popper (RP) phases [4-6] like $\mathrm{K}_{2} \mathrm{NiF}_{4}$ type $\mathrm{La}_{2} \mathrm{NiO}_{4+\mathrm{x}}$ (LNO)-based oxides with higher oxygen ionic conductivity than conventional $\mathrm{LaCoO}_{3}$ based perovskite such as $(\mathrm{LaSr})(\mathrm{CoFe}) \mathrm{O}_{3-\mathrm{x}}(\mathrm{LSCF})$, have also been proposed as possible candidates and are chosen as research subject for this thesis.

\subsection{SOFCs cathode}

For the SOFC with ionic conductive electrolyte, oxygen reduction reaction occurs by accepting electrons from the external circuit at the cathode side, and then the fuel is catalytically oxidized at anode by the oxygen transported through electrolyte. The overall reaction can be written by Kroger-Vink notation as:

$$
\frac{1}{2} \mathrm{O}_{2}(\mathrm{~g})+2 \mathrm{e}^{\prime}+\mathrm{V}_{\mathrm{O}} \rightarrow \mathrm{O}_{\mathrm{O}}^{\mathrm{x}}
$$

For SOFC cathode materials, some requirement can be written as following:[7-9]

(1) Catalytic activity is high enough for oxygen reduction reaction. 
(2) Chemical stability and no interaction with electrolyte.

(3) Sufficient conductivity both for electronic transport and ionic.

(4) Thermal expansion coefficient (TEC) matching with other cell components

Platinum and some other noble metals were used in the early days. Then the perovskites type $\mathrm{La}_{1-\mathrm{x}} \mathrm{Sr}_{\mathrm{x}} \mathrm{MnO}_{3}$ has been studied as a traditional cathode materials for SOFC because of its good compatibility with conventional electrolyte yttrium-stabilized zirconia $\left(\mathrm{Y}_{0.16} \mathrm{Zr}_{0.92} \mathrm{O}_{2.08}\right.$, YSZ) and the considerable electronic conductivity.[10, 11] These kinds of materials can been written as $\mathrm{ABO}_{3}$ and shown in Fig. 1.1. Although for ideal perovskite the relation of the radius between different ions should satisfy Goldschmidt factor $t=r_{A}+r_{O} / \sqrt{2}\left(r_{B}+r_{O}\right)$, the real structures of materials are easily distorted and deviate from the ideal model. LSM has very satisfactory oxygen surface exchange coefficient $(k)$ but poor oxygen diffusion coefficient $(D)$ because its poor ionic conductivity which leads to the oxygen reduction reaction in LSM mainly occurs at triple phase boundary (TPB) area and this would result in sluggish oxygen diffusion rate. Although LSM shows good electronic conductivity, the poor oxygen ionic conductivity and the necessity of high operation temperature because $\mathrm{Mn}^{4+}$ is too stable to create oxygen vacancies in the lattice at intermediate temperature determine it out of fashion for ITSOFCs.

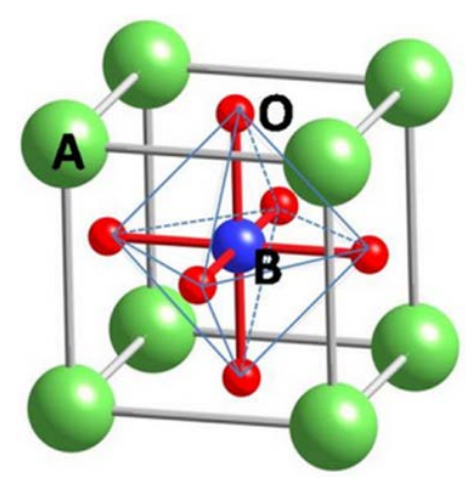

Fig. 1.1 schematic $\mathrm{ABO}_{3}$ perovskite structure.

MIEC is more popularly because the oxygen diffusion of MIEC is enhanced due to the high ionic conductivity and the large amount of oxygen vacancies compare to LSM.[12, 13] The perovskite structure $\mathrm{La}_{1-\mathrm{x}} \mathrm{Sr}_{\mathrm{x}} \mathrm{CoO}_{3-\mathrm{x}}$ (LSC) is earliest found as the MIEC material which has considerable high oxygen diffusivity because of the large amount of oxygen 
vacancies. The LSC cathode has poor chemical stability with YSZ because it reacts with YSZ to create an insulation phase, for example, $\mathrm{La}_{2} \mathrm{Zr}_{2} \mathrm{O}_{7}$ or $\mathrm{SrZrO}_{3}$ at high temperatures. Fortunately new electrolyte materials can be used between YSZ and LSC as the barrier layer like Ceria-based electrolyte (Gadolinia-doped ceria, $\mathrm{Ga}_{0.1} \mathrm{Ce}_{0.9} \mathrm{O}_{2-\mathrm{x}}, \mathrm{GDC}$ ) and LaGaO3-based electrolyte ( $\mathrm{La}_{0.9} \mathrm{Sr}_{0.1} \mathrm{Ga}_{0.8} \mathrm{Mg}_{0.2} \mathrm{O}_{3-\mathrm{x}}$, LSGM). However the thermal expansion coefficient (TEC) of LSC $\left(\sim 22 \times 10^{-6} \mathrm{~K}^{-1}\right)$ is too high to match the electrolytes YSZ $\left(\sim 11 \times 10^{-6} \mathrm{~K}^{-1}\right)$ or GDC $\left(\sim 14 \times 10^{-6} \mathrm{~K}^{-1}\right)$ which would lead to the big crack at the interface between LSCF and YSZ when sintering them together at high temperature even though LSC has good chemical stability with GDC. Partial substitution of Fe for Co to form LSCF perovskite cathode lowers the TEC of LSC down to 14 to $16 \times 10^{-6} \mathrm{~K}^{-1}$. Meanwhile, the chemical stability of LSCF is enhanced by the substitution compare to LSC[14].

Another class MIEC materials which present double perovskite structure having the general formula $\mathrm{AA}^{\prime} \mathrm{B}_{2} \mathrm{O}_{5+x}$ as shown in Fig. 1.2 has been proposed and used as cathode electrode, where A is the rare earth metal and A' is alkaline metal, Co and Mn transition metals are on the B site. These two elements occupy the A site in order due to the big difference between the rare earth metal radius and alkaline metal radius, along c axis layout in $\left[\mathrm{BO}_{2}\right]-\left[\mathrm{A}^{\prime} \mathrm{O}\right]-\left[\mathrm{BO}_{2}\right]-\left[\mathrm{AO}_{\mathrm{x}}\right]$ orders.[15, 16] This kind of materials have very excellent oxygen diffusion coefficients at intermediate temperature, and are well-known catalysts with high activity where the activation of oxygen by dissociation into reactive species is a key part of the catalyst function.[17, 18] However the stability of these materials are not satisfied because at $503^{\circ} \mathrm{C}$ the structure has ordered to disordered transition.[19] Fortunately some rare earth like Niobium substitution has been used effectively to improve stability of the highly oxygen permeable cubic perovskite structure.[20] Deng reported the evaluation of the cubic $\mathrm{B}$ site cation-ordered composition $\mathrm{Ba}_{2} \mathrm{CoMo}_{0.5} \mathrm{Nb}_{0.5} \mathrm{O}_{6-\delta}$ with a mixed Co charge state stabilized by a combination of Mo and Nb doping as a new mixed conductor.[21] 


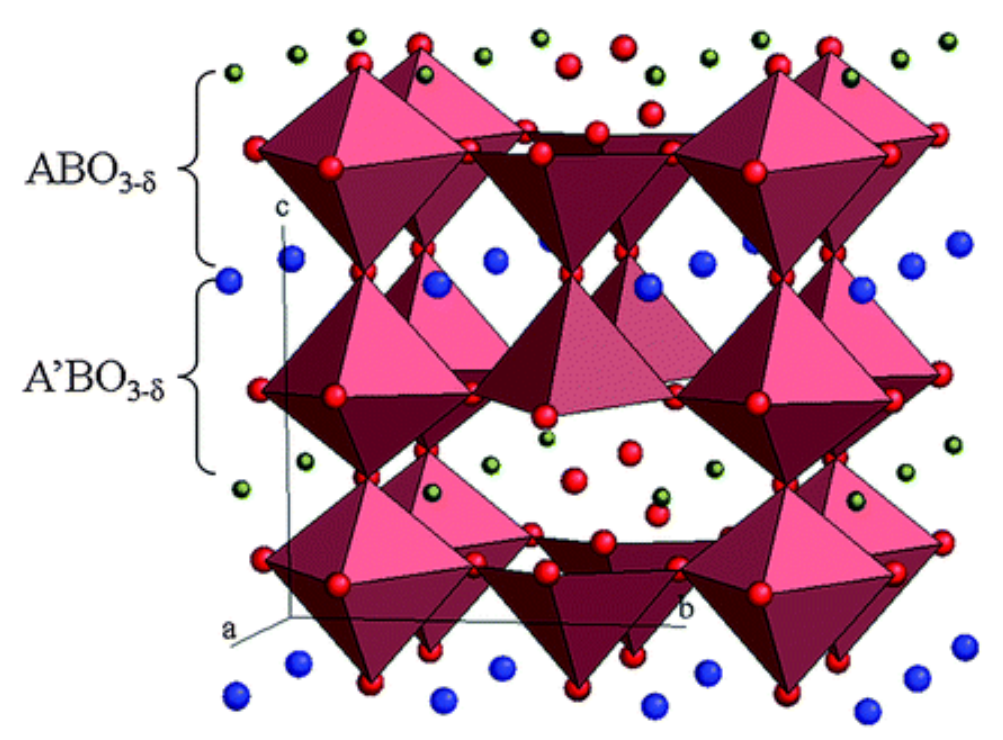

Fig. 1.2 schematic $\mathrm{AA}^{\prime} \mathrm{B}_{2} \mathrm{O}_{5+\mathrm{x}}$ double perovskite phase structure [15]

\subsection{Ruddlesden-Popper phase cathode}

In recent years besides the perovskite and double perovskite type MIEC, the Ruddlesden-Popper phase (R-P) structure lanthanum nickelates family has been brought forth as new cathode alternatives due to their high ionic conductivity and surface reaction kinetics[22-25] to promote the relatively sluggish ORR kinetics after lowering operating temperature from $800 \sim 1000^{\circ} \mathrm{C}$ to IT region $\left(600 \sim 800^{\circ} \mathrm{C}\right)$. The lattice structure of LNO is composed of perovskite layers alternating with $\mathrm{La}_{2} \mathrm{O}_{2}$ rock salt layers. Oxygen hyperstoichiometry is observed and associated to the incorporation of oxygen into the interstitial sites of $\mathrm{La}_{2} \mathrm{O}_{2}$ layers, whose amount depends on the composition, structure, heat treatment history and etc.[30-33]. Such materials exist over a broad range of oxygen nonstoichiometry and that its structural, electric, and magnetic properties are very sensitive to the amount of oxygen contents. Oxygen hyperstoichiometry is confirmed and associated to the incorporation of oxygen atoms into the interstitial sites of $\mathrm{LaO}$ layers. $\mathrm{La}$ and/or $\mathrm{Ni}$ site element substitution have been used to tailor the materials in attempt to improving certain physical parameters, such as the surface exchange, bulk diffusion coefficients and electrical conductivity. The mobility of oxygen in oxides with LNO structure has been studied using a number of theoretical theorems. 


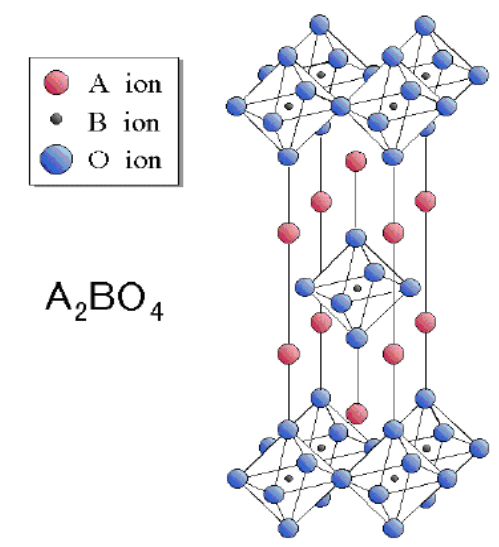

Fig. 1.3 schematic $\mathrm{A}_{2} \mathrm{BO}_{4+\mathrm{x}} \mathrm{RP}$ phase structure

Compared to the popular Co-based perovskite (LaSr)(CoFe)O $\mathrm{O}_{3-\delta}$ (LSCF), nickelates display smaller thermal expansion coefficient and lower volatility so as to offers the advantages in structure compatibility with current IT electrolytes, such as $\mathrm{Gd}_{0.1} \mathrm{Ce}_{0.9} \mathrm{O}_{1.95}$ (GDC) and ( $\mathrm{LaSr})(\mathrm{GaMg}) \mathrm{O}_{3-\delta}$ (LSGM), and chemical stability during long-term operation. ${ }^{[14-16]}$ Such layered structure is able to accommodate a wide range of oxygen stoichiometry from significant excess to deficient. This feature provides a broad freedom to engineer those compounds in terms of chemical diffusion $(D)$, surface oxygen exchange coefficients $(k)$, electrical conductivity and so on to meet application requirement. ${ }^{[17-19]}$ As a result of the major progress in R-P phase cathode development, encouraging performances have been achieved in several groups with various compositions, such as $\mathrm{Nd}_{2} \mathrm{NiO}_{4+\delta},(\mathrm{LaPr})_{2} \mathrm{NiO}_{4+\delta}, \mathrm{La}_{2}(\mathrm{NiCo}) \mathrm{O}_{4+\delta}$, and etc. ${ }^{[20-24]}$ Owing to the good balance between catalytic activity and chemical stability, $\mathrm{La}_{2} \mathrm{NiO}_{4+\delta}$ (LNO) stands out as a promising candidate to fulfill the near future application most possibly. ${ }^{[19,21]}$ Considering the relatively high electronic and ionic conductivities, good electro-catalytic properties and compatible thermal expansion coefficient with commonly used electrolytes, Lanthanum nickelates with R-P structure has been chosen as cathode materials for this thesis.

\subsection{Dense electrode EIS}

Porous electrode symmetrical cells are usually characterized by electrochemical impedance spectroscopy. Different impedance arc presents different ORR process. However, it is hard to distinguish each process accurately for porous electrode cells from 
EIS directly due to the complex nature of the polarization resistance which includes influence from material composition, bulk diffusion, surface exchange as well as microstructure. Thus the dense electrode/electrolyte/dense electrode sandwich configuration was adopted in this thesis even though in practice porous electrode is chosen over the dense electrode.

In the ideal condition for dense electrode is that the resistance from surface exchange is the same for electrodes with different thickness, the contribution from bulk diffusion and surface exchange can be distinguished by plotting the polarization resistance with the thickness. The intercept with y-axis will be the contributions from surface and interface exchange, and the slope of the straight line characterizes the ionic bulk diffusion resistance. Besides, by using the specific EIS fitting circuit, the ionic conductivity and chemical capacitance can be derived from the spectra, which can lend us credit after comparing those values with known parameters reported in the literature. One the other hand, a porous LNO layer was added onto the surface of some dense electrode cells to decrease the surface exchange resistance. Through this method, the validity of the attribution we did based on dense electrode alone can be double checked. And any newly present EIS spectra will be analyzed based on the known macro-parameters.

By using the dense electrode, the surface area, the thickness of electrode, the interface between electrode and electrolyte and lastly the $3 \mathrm{~PB}$ are theoretically well-defined. Through this method, there is a good chance to distinguish the contribution from surface exchange, ionic and electronic bulk transport and ion interface exchange.

\subsection{Objectives of this work}

Oxygen reduction at the cathode is considered as the main rate limiting factor in the performance of the whole operating system. Fundamental studies of the ORR mechanisms are important and necessary. The motivation of this thesis is to further understand the fundamental of the ORR kinetics of LNO cathode. 
(1) The overall ORR and main rate determining steps of LSNO needs to be determined by EIS testing.

(2) Due to the surface process is more complicated compared to bulk characterization; the surface kinetics investigation of LSNO on symmetric cells with simple geometry will be studied.

(3) With the fundamental understanding of surface kinetics, the performance improvement will be attempted by the active element substituted. 


\section{Chapter 2: Experimental methods}

\subsection{Fabrication cathode materials by Sol-Gel synthesis}

The investigated powders were synthesized by EDTA-citric Sol-Gel method. Stoichiometric nitrates (Alfa Aesar or Acros Organics) together with citric acid (Alfa Aesar) were dissolved into distilled water separately. EDTA powders (Fisher Scientific) as complexant was dissolved into diluted ammonia water (the mole ratio of metal cation:citricacid:EDTA=1:1.5:1). The solutions above were mixed together followed by adjusting $\mathrm{PH}$ to 8 , then held at $\sim 80^{\circ} \mathrm{C}$ and stirred until gelation. The gel was heated to 600 oC to decompose nitrates and organic residual. The resultant powders were sintered in air at $1000 \mathrm{oC}$ for $4 \mathrm{~h}$ and examined by X-ray diffraction (XRD, PANalyticalX'pert PRO, Cu $\mathrm{K} \alpha$ radiation) to check phase purity.

\subsection{Fabrication dense double layers by modified spray -pressed}

The resultant powders along with polyvinyl butyral (PVB) and fish oil at the weight ratio of 100:2:1.5 was added into ethanol (5 g powders to $30 \mathrm{~mL}$ ethanol), then ball-milled for $24 \mathrm{~h}$ to produce suspension which was air-brushed onto both sides of electrolyte to fabricate thin layer. In brief, the electrolyte in 1.5g was dry pressed under 50MPa in a 16.5 mm die. The suspension was evenly sprayed to electrolyte surface, followed by an intermediate pressing of 200MPa. The sample was taken out and inserted back to the die with the uncoated surface facing outside this time. The spray process was repeated, followed by a final pressing at 300MPa. Electrode/electrolyte/electrode sandwiches were sintered to $1300^{\circ} \mathrm{C} 4 \mathrm{~h}$ for densification. In order to avoid any possible element-enrichment in the surface, the sintered pellets were polished manually using grind paper then $2 \mu \mathrm{m}$ polishing cloth. The removed thickness for each sample could not be precisely controlled,

but was estimated in the range of $30 \sim 70 \mu \mathrm{m}$ after inspection by scanning electron microscopy (SEM, Hitachi S-4700F), depending on individual samples. 


\subsection{Fabrication symmetrical cells}

To make the cathode slurry, the as-prepared powders were blended with an ink vehicle (Fuel Cell Materials Co.) at the weight ratio of powders:vehicle=10:11, then ground in a mortar until homogeneous slurry was formed. Gadolinia-doped ceria $\left(\mathrm{Gd}_{0.1} \mathrm{Ce}_{0.9} \mathrm{O}_{1.95}\right.$, GDC, from Fuel Cell Materials Co.) slurry was produced in the same method and screenprinted to both sides of the sintered yttria-stabilized zirconia $\left(\mathrm{Y}_{0.16} \mathrm{Zr}_{0.92} \mathrm{O}_{2.08}\right.$, YSZ, from NextechCo.) pellets as buffer layer, followed by sintering at $1350^{\circ} \mathrm{C}$ for $3 \mathrm{~h}$. Afterward, the cathode slurry was screen-printed symmetrically onto the GDC layer with an area of $0.7 \mathrm{~cm}^{2}$, followed by sintering at $1050^{\circ} \mathrm{C}$ for $2 \mathrm{~h}$. Pt mesh was attached onto the cathode by Pt paste as the current collector.

\subsection{Characterization}

The X-ray diffraction (XRD, PANalyticalX'pert PRO and Bruker AXS, $\mathrm{Cu} \mathrm{K \alpha}$ radiation) test is conducted to examine purity of phase. To analyze XRD spectra commercial software Jade 5 is used.

The conductivity testing is tested by Van der pauw or 4-probe DC methods. Electrolyte or anode pellets for conductivity tested were dry pressed using dies with different diameters followed by sintering at different temperatures. Four silver wires were bonded to the surface of samples using silver paste symmetrically, followed by heating to $850{ }^{\circ} \mathrm{C}$. The measurement was carried out in a temperature-programed tube furnace. The gas composition was controlled by mass flow controller. The electrical conductivity data was collected using Keithley, with sourcing current of $10 \mathrm{~mA}$ and monitoring the voltage.

The electrochemical performance is characterized by electrochemical impedance spectroscopy (EIS) through solartron 1286\&1260 or Autolab Model. EIS characterization was conducted on those symmetric cells in 4 different $P_{\mathrm{O} 2}\left(\log \left(P_{\mathrm{O} 2} / \mathrm{atm}\right)=-0.678,-1,-1.5\right.$, 2) atmospheres by Solartron 1287 electrochemical interface and 1260 impedance analyzer at open circuit condition (OCV) over the frequency range from $0.1 \mathrm{~Hz}$ to $1 \mathrm{MHz}$. The 
designed $P_{\mathrm{O} 2}$ was produced by mixing air with $\mathrm{N}_{2}$ controlled via mass flow meters (Alicat Scientific). An AC perturbation signal of $20 \mathrm{mV}$ was applied in each measurement. The resulting spectra were deconvoluted using Z-view software.

Scanning electron microscopy (SEM, JEOL JSM-7600F) is used to observe the microstructure of samples. 


\section{Chapter 3: Investigation of Sr-doped LNO on porous symmetrical cells}

In this chapter, porous symmetrical cells of $\mathrm{La}_{2-\mathrm{x}} \mathrm{Sr}_{\mathrm{x}} \mathrm{NiO}_{4+\delta}(0 \leq \mathrm{x} \leq 0.4)$ (LSNO) were fabricated by sol-gel method. To further clarify the effect of Sr doping on the electrode performance of LNO cathode, or more specifically, how it affects the bulk diffusion and surface exchange kinetics in the cathode ORR, LSNO cathode are characterized by EIS in different $P_{\mathrm{O} 2}$ in temperature range of $600 \sim 800^{\circ} \mathrm{C}$. The spectra were analyzed based on the impedance model introduced by Adler et al. The rate limiting steps for ORR were proposed and the responsible reasons were discussed.

\subsection{Characterization of basic physic properties of different candidates}

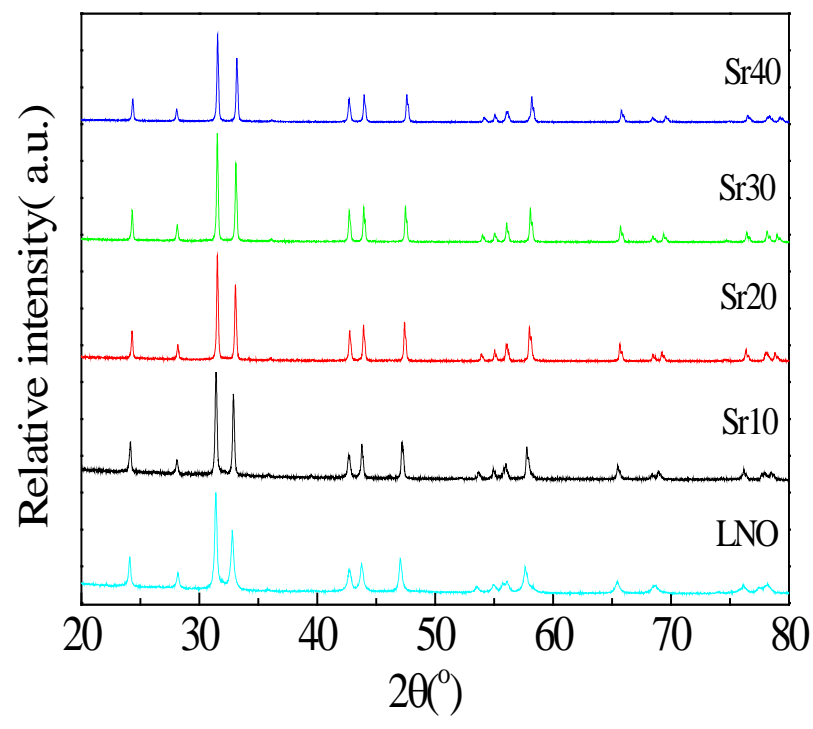

Fig. 3.1 XRD patterns for $\mathrm{La}_{2-\mathrm{x}} \mathrm{Sr}_{\mathrm{x}} \mathrm{NiO}_{4+\delta}(\mathrm{x}=0,0.1,0.2,0.3,0.4)$ samples.

Fig. 3.1 shows the XRD spectra from the powder samples of $\mathrm{La}_{2-\mathrm{x}} \mathrm{Sr}_{\mathrm{x}} \mathrm{NiO}_{4+\delta}(\mathrm{x}=0$, $0.1,0.2,0.3,0.4)$. Each pattern matches the $\mathrm{K}_{2} \mathrm{NiF}_{4}$ structure, indicating pure R-P phase is obtained for all nickelate samples in this study.

Fig. 2 shows the electrical conductivities of $\mathrm{La}_{2-x} \mathrm{Sr}_{x} \mathrm{NiO}_{4+\delta}$. Sr doping enhanced the conductivity regardless of the doping level. The highest one is achieved with Sr10. But 
with heavier doping, the conductivity decreases gradually, which is different from the results reported by Nakamura[37] that the conductivity increased with Sr content. Although sintered at $1450^{\circ} \mathrm{C}$, the pellets are still not completely dense. The relative density is determined by Archimedes method: 95.7\% for LNO, 94.2\% for Sr10, 93.6\% for Sr20, 92.7\% for Sr30, 91.9\% for Sr40. Therefore, the difference shown in this work should be partially from the relative density. From 600 to $800^{\circ} \mathrm{C}$, the conductivity decreases with temperature, which is more significant for LNO, Sr10 and Sr20 compared to Sr30 and Sr40. It primarily results from the reduction of electron hole density, accompanying by the decrease of $\delta$ as temperature increases.[37-40]

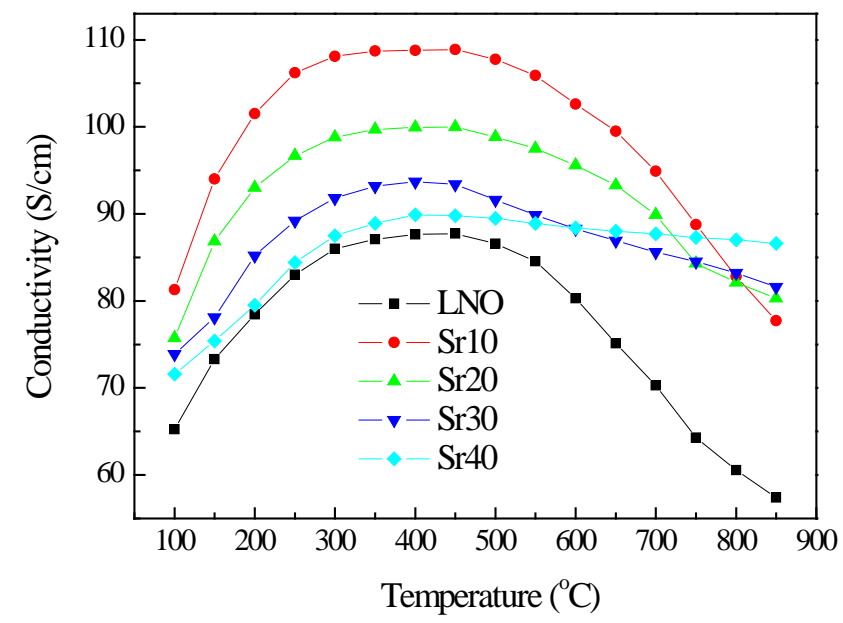

Fig. 3.2 Electrical conductivities for $\mathrm{La}_{2-\mathrm{x}} \mathrm{Sr}_{\mathrm{x}} \mathrm{NiO}_{4+\delta}$ tested in air.

Fig. 3a shows the cross-section of the LNO electrode. GDC is inserted between cathode and YSZ electrolyte to promote the performance. The typical thickness of the cathode layer is $\sim 20 \mu \mathrm{m}$. Shown in Fig. 2b-f are the interfaces of GDC/nickelates. The bond between GDC and nickelate is good in each sample. The average particle size is round $0.4 \mu \mathrm{m}$ for LNO, and roughly $0.7,0.7,0.5,0.4 \mu \mathrm{m}$ for Sr10, 20, 30 and 40, respectively. 

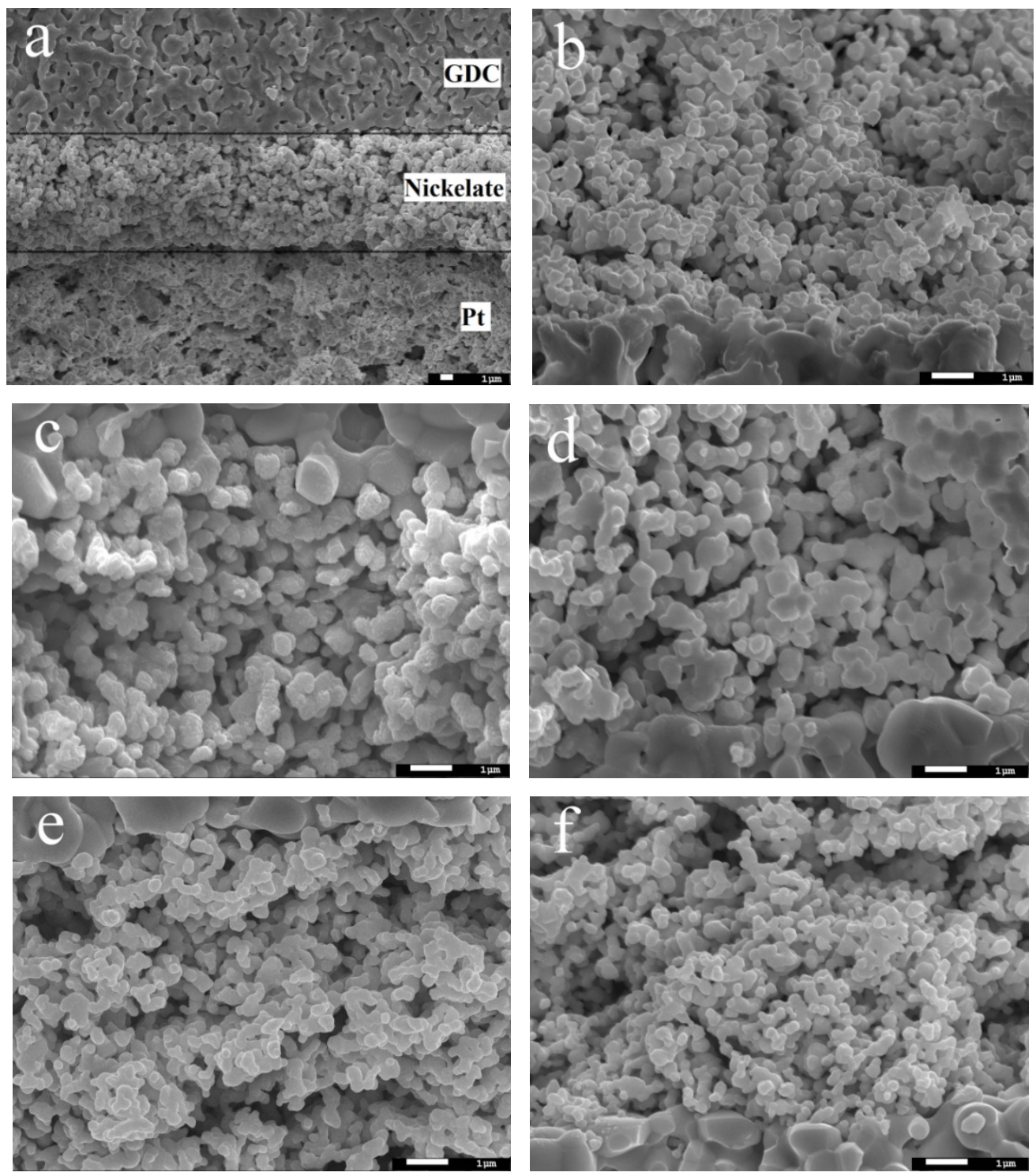

Fig. 3.3 Cross-section view ofSr10 electrode (a), and the nickelates/GDC interface: LNO

(b), Sr10 (c), Sr20 (d), Sr30 (e) and Sr40 (f).

\subsection{Decreased performance upon Sr doping and the co-limited electrode}

process

Fig. 3.4 shows the EIS profiles for those samples measured in air at $700^{\circ} \mathrm{C}$. The spectra were analyzed based on the impedance model introduced by Adler et al.[41, 42] The ohmic resistances have been subtracted. The spectrum for LNO features half tear shape, showing a $45^{\circ}$ straight line at high frequency (HF) and a semi-circle in the low frequency 
(LF) domain. Straight line at HF limit as such is a prominent indicator of diffusion limitation. And the half tear-shaped spectrum is usually assigned to the Gerischer impedance depicting a situation controlled by a chemical reaction and the subsequent mass diffusion.[43, 44]
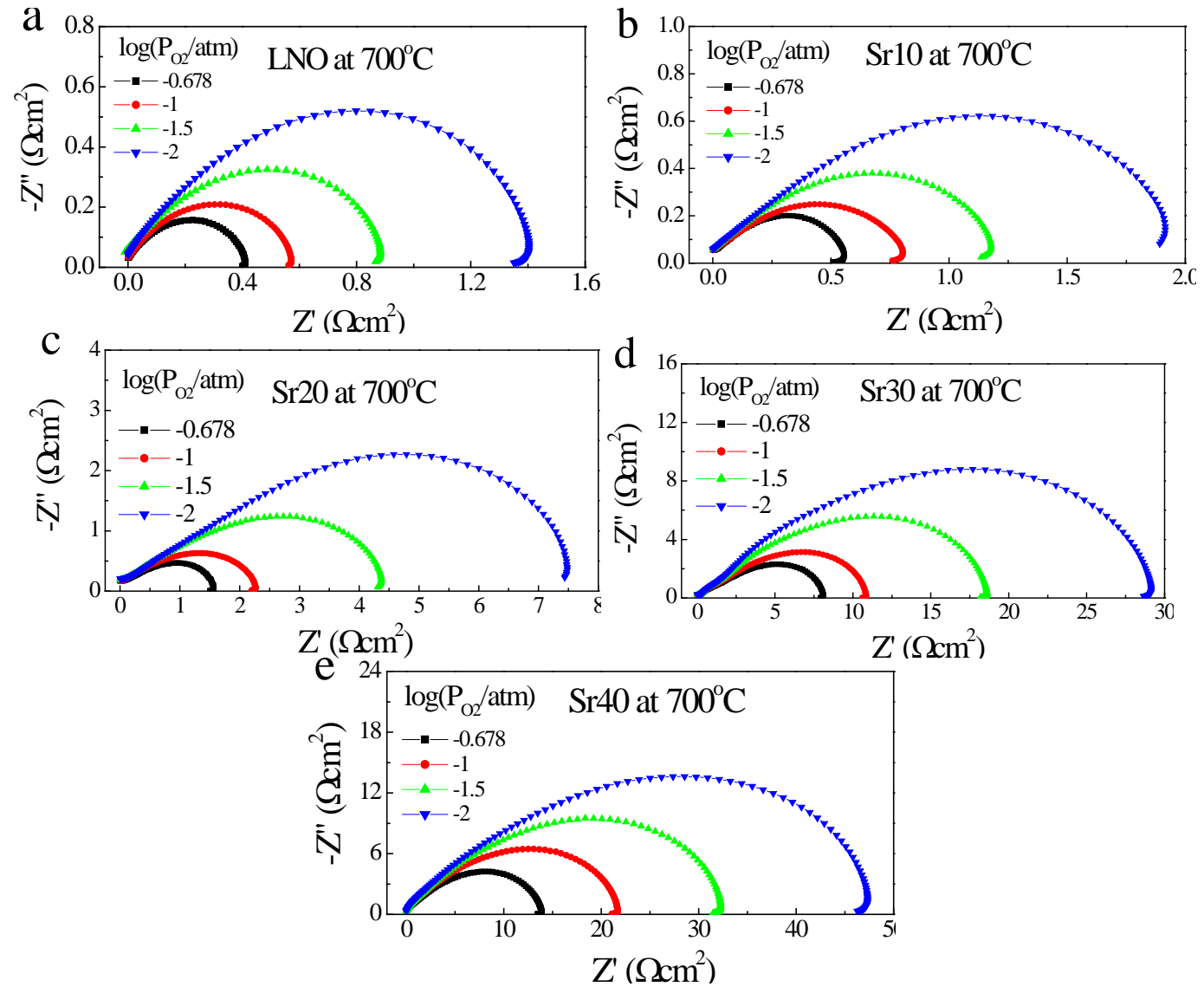

Fig. 3.4 EIS spectra for different nickelates at $700^{\circ} \mathrm{C}$ in various $P_{\mathrm{O} 2}$.

Rooting in this Gerischer element, Adler et al.[41] built a model (referred as ALS model) to describe the impedance response of a porous MIEC electrode with an extended active zone with details including polarization resistance, chemical capacity, characteristic length and etc. Judged by the reported high $D$ and $k$ values for LNO and the spectrum feature observed here,[27, 45]it is suggested that the electrode process could be co-limited by surface exchange and diffusion in LNO cathode. LNO spectrum is then fitted by the ALS model. Likewise, for Sr doped samples similar half tear-shaped profiles can be seen in Fig. 3.4, but with the slope of the HF straight line decreased and the LF part arc more 
suppressed. It is noted that for Sr30 and Sr40, an additional small arc appears and overlaps with the straight line at the HF limit, which can be found more easily in the corresponding Bode plot in Fig. 4a, with two peaks occurring at $\sim 10^{4} \mathrm{~Hz}$ and between $10 \sim 100 \mathrm{~Hz}$.

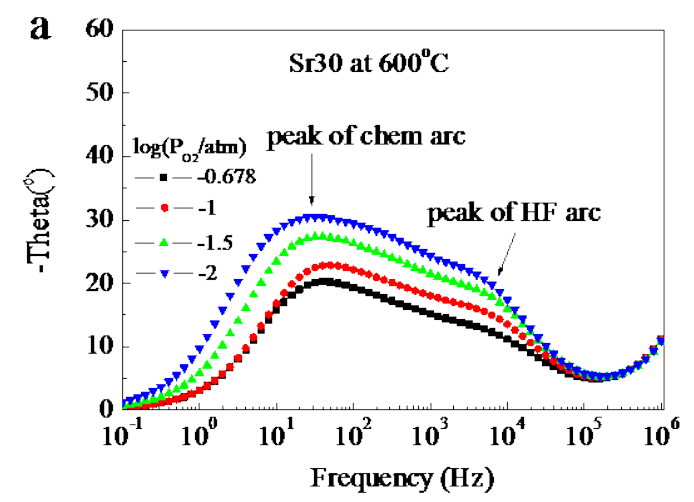

b

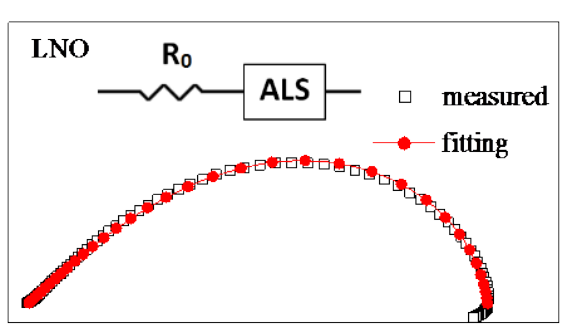

C

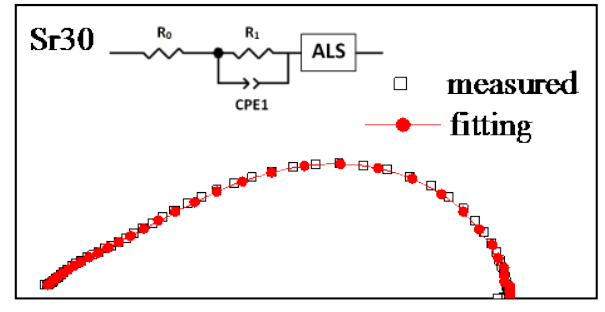

Fig. 3.5 Bode plot for Sr30 (a), and ALS fitting for LNO (b) and Sr30 (c).

Eqs.3-1 and 3-2 express the impedance and capacitance of the co-limited chemical processes in the ALS model, inclusive of the surface and bulk diffusion contributions.

$$
\begin{gathered}
Z(w)=\frac{R_{\text {chem }}}{\sqrt{1+\left(j w t_{\text {chem }}\right)^{\alpha}}} \\
C_{\text {chem }}=\frac{t_{\text {chem }}}{R_{\text {chem }}}
\end{gathered}
$$

$R_{\text {chem }}$ is the resistance of chemical contribution to the cell impedance, $t_{\text {chem }}$ the characteristic relaxation time related to the solid state diffusion and oxygen surface exchange, $C_{\mathrm{chem}}$ the capacitance associated with the change of oxygen stoichiometry in the MIEC. A parameter, $\alpha$, is adopted here to account for the non-ideal behavior as shown in $\mathrm{Sr}$ doped samples. Such practice has been found more applicable for accurate fitting and the concept has been addressed by Boukamp et al.[43, 46-48] Besides, for Sr30 and Sr40 at 
$600 \sim 700^{\circ} \mathrm{C}$, a RC element is added in series to the ALS impedance to represent the HF arc response at shown in Fig. 4a. At higher temperature where the HF arc disappears most probably due to the large thermal-activated improvement in interface exchange rate, satisfactory fitting can be obtained using the ALS element alone. As examples, the fitting spectra of LNO, Sr30 in air at $700{ }^{\circ} \mathrm{C}$ and the related equivalent circuits are shown in Fig. $4 \mathrm{~b}$ and c, respectively.

Table 3-1 Summary of resistances, capacitances, characteristic frequencies from ALS fitting.

\begin{tabular}{|c|c|c|c|c|c|c|c|}
\hline \multirow[b]{2}{*}{$\mathrm{T}=700^{\circ} \mathrm{C}$} & \multirow[b]{2}{*}{ Total $R\left(\Omega \mathrm{cm}^{2}\right)$} & \multicolumn{3}{|c|}{$\mathrm{O}^{2-}$ transfer nickelates/GDC } & \multicolumn{3}{|c|}{ chem process } \\
\hline & & $R_{\mathrm{IT}}\left(\Omega \mathrm{cm}^{2}\right)$ & $C\left(\mathrm{mF} / \mathrm{cm}^{2}\right)$ & $(\mathrm{Hz})$ & $\begin{array}{c}R_{\text {chem }}(\Omega \\
\left.\mathrm{cm}^{2}\right)\end{array}$ & $C_{\text {chem }}\left(\mathrm{mF} / \mathrm{cm}^{2}\right)$ & $\alpha$ \\
\hline LNO & 0.41 & - & - & - & 0.41 & 14.1 & 0.96 \\
\hline Sr10 & 0.61 & - & - & - & 0.61 & 15.9 & 0.90 \\
\hline Sr20 & 1.74 & - & - & - & 1.74 & 2.1 & 0.80 \\
\hline Sr30 & 8.1 & 0.83 & 0.011 & 13000 & 7.3 & 0.20 & 0.90 \\
\hline Sr40 & 14.4 & 1.92 & 0.091 & 5400 & 12.5 & 0.15 & 0.88 \\
\hline
\end{tabular}

The measured polarization resistances $\left(R_{\mathrm{p}}\right)$ and fitting results for all samples at $700^{\circ} \mathrm{C}$ are tabulated in Table 3-1. The best performance is obtained with the undoped LNO sample, which reads $0.41 \Omega \mathrm{cm}^{2}$ and is a competitive output for the intermediate temperature cathodes at $700{ }^{\circ} \mathrm{C}$.[44, 49] The polarization resistance increases with doping level. Those results are consistent with the ones reported by Aguadero et al.[50] According to the fitting results, the small capacitances and the large characteristic frequencies for the HF arcs of Sr30 and Sr40 indicate that those arcs can be reasonably associated to a charge transfer process.[51-53] The incorporation of oxygen into cathode lattice has been taken into account in the ALS element. Meanwhile, the electron transfer from current collector to the cathode must not be the case because Sr30 and Sr40 possess higher electrical conductivities than LNO.[37] In fact, a similar situation has been found on the LSCF electrode: a small HF arc was observed when replacing GDC with the less conductive electrolyte YSZ, and attributed to the slowed oxygen exchange rate between LSCF and 
YSZ.[54] Such arcs herein are therefore assigned to the oxygen ion transfer process between lanthanum nickelates/GDC. The occurrence of such arcs should be determined by the transfer rate in the interface and attributed to the decrease of oxygen diffusivity of the Sr doped cathodes, since GDC barrier layer is the same in each sample from LNO to Sr40.

The chemical capacitance in Table 3-1 stems from the change of oxygen content in the oxide cathode when experiencing potential vibration during EIS testing. Because oxidation/reduction of those nickelates is accompanied by the increase/decrease of compensating holes, the variation of oxygen stoichiometry, without violating the electroneutrality, can be significant, thereby leading to considerable capacitance.[55] More specifically in the porous electrodes, it is literally determined by the microstructure, a thermodynamic factor $(f)$ representing how facile the stoichiometry changes with $P_{\mathrm{O} 2}$ and a characteristic length $\left(l_{\delta} \propto \frac{D}{k}\right)$ describing how far the active reaction zone stretches away from the cathode/GDC interface ( $c_{\text {chem }} \propto \frac{l_{\delta}}{f}$ ).[55] This capacitance can be used as an indicator, showing whether the electrode bulk is active or not. The evolution of such capacitance under $P_{\mathrm{O} 2}$ change is shown in Fig. 5. For each single sample, the capacitance increases with decreasing $P_{\mathrm{O} 2}, 57 \mathrm{mF} / \mathrm{cm}^{2}$ for $\mathrm{LNO}$ at $1 \% \mathrm{O}_{2}$. It is found in a variety of composition and transport studies of lanthanum nickelates that the ionic conductivity or $D$ displays a dependence of $\sim 1 / 6$ to $P_{02},[25,40,56]$ whereas the surface reaction processes in general exhibit greater dependency on $P_{\mathrm{O} 2}$, such as a reaction order of 1 for the adsorption process. In this case, lowering $P_{\mathrm{O} 2}$ could diminish surface kinetics more substantially than the diffusion process, resulting in a bigger $l_{\delta}$. Meanwhile, Vashook et al.[38]found that the oxygen stoichiometry of $\mathrm{La}_{2-\mathrm{x}} \mathrm{Sr}_{\mathrm{x}} \mathrm{NiO}_{4}$ varies more facilely with reducing $P_{\mathrm{O} 2}$, leading to a reduced $f$ at lowered $P_{\mathrm{O} 2}$. The same was also confirmed by Kim et al. through the impedance studies of thin film LNO.[57] Consequently, the resultant $C_{\text {chem }}$ is expected to enlarge with decreasing $P_{\mathrm{O} 2}$, which is consistent with the results shown in Fig. 5.The different values for $C_{\text {chem }}$ between those doped samples hinge on the influence of $\mathrm{Sr}$ doping on the amount of interstitial oxygen. The change of oxygen stoichiometry with $P_{\mathrm{O} 2}$ (or the equivalent $P_{\mathrm{O} 2}$ from applied potential in EIS) in lanthanum nickelates is reported to turn harder rapidly with reducing $\delta$ after Sr doping, and almost keeps unchanged in Sr40 sample 
which possesses little excess oxygen ( $\delta=0 \sim 0.05$ ) when measured in the similar conditions as in this work.[58] Such tendency would lead to diminished $C_{\text {chem. }}$ However, it is noteworthy that the measured $C_{\text {chem }}$ could otherwise come from the surface adsorbents when the bulk stoichiometry change turns hard, as will be discussed below.

Table 3-2. Estimated characteristic lengths in the bulk.

\begin{tabular}{ccccccc}
\hline & & $600{ }^{\circ} \mathrm{C}$ & $650{ }^{\circ} \mathrm{C}$ & $700{ }^{\circ} \mathrm{C}$ & $750{ }^{\circ} \mathrm{C}$ & $800{ }^{\circ} \mathrm{C}$ \\
\hline$l_{\delta}(\mu \mathrm{m})$ & LNO & 7.8 & 5.7 & 3.3 & 3.2 & 2.1 \\
at $0.21 \mathrm{~atm}$ & Sr10 & 6.8 & 4.9 & 3.8 & 2.6 & 1.9 \\
$l_{\delta}(\mu \mathrm{m})$ & LNO & 11.2 & 9.1 & 7 & 5.2 & 3.8 \\
at $0.01 \mathrm{~atm}$ & Sr10 & 10 & 7.5 & 5.7 & 4.3 & 3.2 \\
$f(0.21 \mathrm{~atm})$ & & 900 & 788 & 675 & 563 & 450 \\
$f(0.01 \mathrm{~atm})$ & & 500 & 425 & 350 & 275 & 200 \\
\hline
\end{tabular}

$f$ is averaged over the values from Ref. 37 and 41.

Based on $C_{\text {chem }}$ in this work, and estimated $f$ values from those for LNO reported by Kim and Jeon,[25, 57] the characteristic lengths can be calculated using Eq. 3,[55] (note: $f$ from Adler's work has a different form from those in Ref [25, 57]. Simple mathematical conversion yields $f$ (Adler) $=0.5 f$ (Kim) for R-P phase lanthanum nickelates)

$$
l_{\delta}=\frac{\mathrm{R} T}{4 \mathrm{~F}} \frac{C_{\mathrm{chem}} V_{\mathrm{m}} f}{(1-\varepsilon)}
$$

Where $V_{\mathrm{m}}$ is the mole volume of the nickelate and $\varepsilon$ is the porosity of electrode (roughly estimated as 0.3 from the SEM pictures), R, F and $T$ remain the usual physical meanings.

$l_{\delta}$ for LNO under $P_{\mathrm{O} 2} 0.21$ and 0.01atm are summarized in Table 3-2. $f$ values used in the calculation are listed as well ( $f$ in the table is $1 / 2$ of its original value in Kim and Jeon's work). The characteristic length at $700{ }^{\circ} \mathrm{C}$ is $1.7 \mu \mathrm{m}$ in air, comparable to the typical MIEC cathode $(\mathrm{LaSr}) \mathrm{CoO}_{3}$ with $l_{\delta}=2 \mu \mathrm{m}$ at the similar condition.[41] Lowering $P_{\mathrm{O} 2}$ increases $l_{\delta}$, just as analyzed above on the basis of the different dependencies for $D$ and $k$ to 
$P_{\mathrm{O} 2} . f$ for the doped nickelates is not available in the literature so far. In addition, related stoichiometry measurements by different authors scatter to some extent,[38, 58] making approximation of $f$ from stoichiometry data and the resultant $l_{\delta}$ unreliable. As a rough estimation, $l_{\delta}$ for Sr10 are directly computed using the same $f$ from LNO. The accurate lengths for this sample should be larger than the calculated ones listed in Table II, given that $f$ for Sr10 are actually bigger than those for LNO. Those significant bulk active lengths in Table II work to justify our earlier supposition on the reaction \& diffusion co-limiting nature and the use of ALS model for EIS fitting. Since the difference of such thermodynamic factor between doped samples and LNO baseline becomes progressively larger with increasing doping level, it is not instructive to use the same $f$ on the heavier doped samples. $l_{\delta}$ for Sr20-40 are left out in the table.

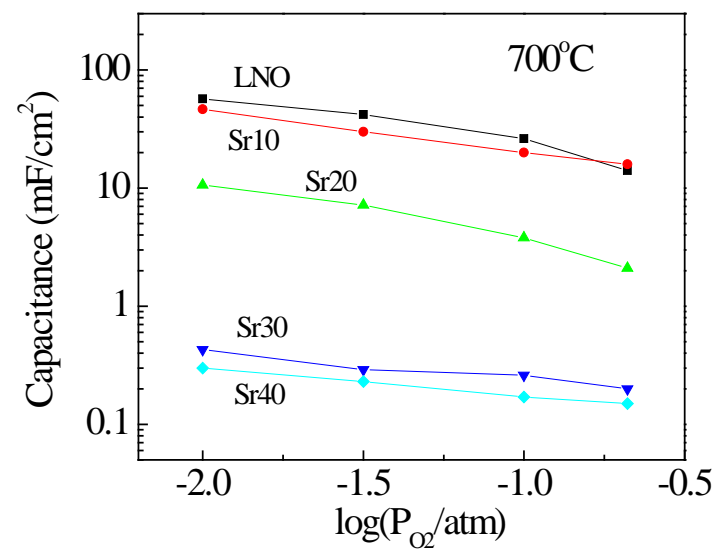

Figure 3.6 The evolution of chemical capacitance with $P_{\mathrm{O} 2}$ at $700^{\circ} \mathrm{C}$.

Generally speaking, the magnitude of $C_{\text {chem }}$ for the end members Sr30 and Sr40 in Fig. 3.6 are not necessarily greater than those measured from TPB-controlling cathodes. However, as reported by Lu et al.[59] in the continuation work on the original ALS model, those ALS spectra for Sr30 and Sr40 can also be fulfilled by considering the parallel surface transport path when the cathode materials display relatively poor bulk transport coefficients. In this case, $C_{\text {chem }}$ originated from the surface adsorbents can be orders of magnitude lower compared to the bulk-related ones. 
Given Sr doping decreases $D$ value, the occurrence of the extended active bulk in LNO and Sr10, which is essentially determined by the ratio of $D / k$, implies that $k$ is also reduced upon 5\% A site Sr doping. But for the heavier doping levels, without any specific $f$ values or other relevant information, the magnitude of $l_{\delta}$ and the change of it towards $\mathrm{Sr}$ cannot be presented quantitatively. Nevertheless, a speculation based on limited wisdom on EIS profiles from independent results in literature may be made toillu strate the change of surface kinetics qualitatively on those materials. For Sr20-40 samples, the spectra all consist of a straight line in the high frequency limit. As stated before and from a variety of EIS studies on cathodes, such straight line almost always coincides with a diffusion limitation in a significant diffusion length,[42, 43, 60, 61] and sometimes is even referred to as the high frequency Warburg response directly. More specifically, in the theoretical treatment of the Gerischer-type impedance on porous electrodes, Nielsen et al.[44] showed that the appearance of such impedance requires the co-existence of the surface oxygen reaction and diffusion processes in the thick porous cathode model, or in other words a decent $l_{\delta}$. When those two contributions are off-balanced and one process is vastly superior to the other, e.g. the bulk diffusion process being much faster, the whole electrode is active and the spectrum will deviate from the half tear shape and reduce to a single arc in the limiting case. On the other hand, if we assume the surface reaction is greatly better, $l_{\delta}$ would shrink substantially. This would turn the electrolyte/electrode interface into the primary reaction area where the spillover mechanism near 3PB takes place and shortcuts the significant bulk/surface diffusion pathway. On this occasion, the suppressed arc instead of the half-tear shaped spectrum will also be expected, which has usually been confirmed in most 3PB limited electrodes like LSM.[51] In view of those implications of the Gerischer behavior, it seems that $D$ and $k$ are most possibly well balanced also in those Sr20-40 specimens. $k$ is progressively reduced by $\mathrm{Sr}$ doping as $D$ is. In this sense, for all $\mathrm{Sr}$ doping samples, the relative importance of surface exchange and bulk/surface diffusion to the overall performance may be essentially similar to each other by adjusting $l_{\delta}$. It is thus suggested that sacrificing $D$ to improve $k$ through $\mathrm{Sr}$ doping, even if one could, may not effectively enhance the performance because neither of them is the sole determining factor. 


\subsection{Reaction order and surface limiting steps}

The RLS in surface exchange is investigated through the $P_{\mathrm{O} 2}$-dependent polarization resistance. The reaction orders $(n)$ in the relationship of $1 / R \propto P_{\mathrm{O} 2}^{n}$ for the electrode process fall into 1/3 to 1/2 for all cathodes as shown in Fig. 3.7a-c.
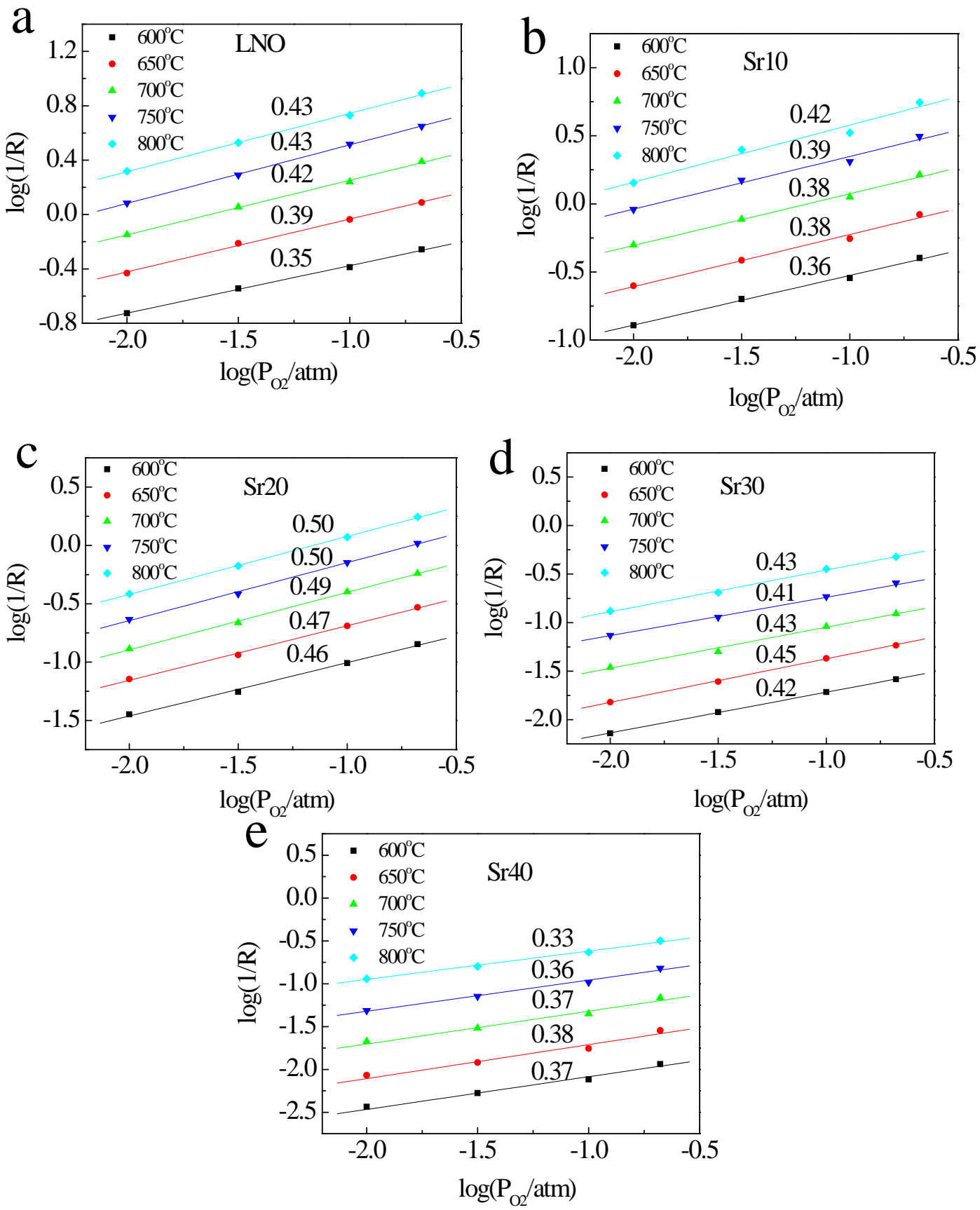

Figure 3.7: Reaction orders from the overall polarization resistances for nickelates: LNO (a), Sr10 (b), Sr20 (c), Sr30 (d) and Sr40 (e). 
Due to the polarization resistances consists of surface and bulk contributions, the related $n$ is influenced by both of them. The $P_{\mathrm{O} 2}$ dependency for the diffusion contribution is determined by the variation of $D$ (or $\delta$ ) towards the change of $P_{\mathrm{O} 2}$. As stated before, $D$ (or $\delta$ ) is reported to depend on $P_{\mathrm{O} 2}$ by a factor around or less than 1/6.[56, 62] Therefore, oxygen dependency from the surface exchange reaction part needs to be over $1 / 2$ to yield the measured values of 1/3 1/2.

$\begin{array}{ccc}\text { Oxygen surface exchange: } & \mathrm{O}_{2} \rightarrow 2 \mathrm{O}_{\mathrm{ads}} \stackrel{\mathrm{e}}{\rightarrow} \mathrm{O}_{\mathrm{ads}}^{-} \stackrel{\mathrm{e}, \mathrm{V}_{\mathrm{i}}^{\times}}{\longrightarrow} \mathrm{O}_{\mathrm{i}}^{\prime \prime} & \\ \text { Step 1 } & \mathrm{O}_{2} \leftrightarrow 2 \mathrm{O}_{\mathrm{ads}} & \mathrm{n}=1 \\ \text { Step 2 } & \mathrm{O}_{\mathrm{ads}}+\mathrm{e} \leftrightarrow \mathrm{O}_{\mathrm{ads}}^{-} & \mathrm{n}=3 / 8 \\ \text { Step 3 } & \mathrm{O}_{\mathrm{ads}}^{-}+\mathrm{e}+\mathrm{V}_{\mathrm{i}}^{\times} \leftrightarrow \mathrm{O}_{\mathrm{i}}^{\prime \prime} & \mathrm{n}=1 / 8 \\ \text { Step 3, } & \mathrm{O}_{\mathrm{ads}}^{-}+\mathrm{e}+\mathrm{V}_{\mathrm{o}}^{*} \leftrightarrow \mathrm{O}_{\mathrm{o}}^{\times} & \mathrm{n}=1 / 8\end{array}$

The surface exchange process is carried out in several sequent steps as shown above. The reaction orders are calculated using the routine reported elsewhere by Heuveln et al.[51, 63, 64] and listed after each elementary reaction. Burriel et al.[65] observed that the surface exchange reaction was 2 orders of magnitude faster in a-b plane than along c-axis in the (001)-oriented epitaxial LNO thin film. As a result, for those specimens with apparent excessive oxygen such as LNO and Sr10, interstitial vacancy in LaO layer instead of oxygen vacancy in $\mathrm{ABO}_{3}$ layer is taken as the primary active species, as shown in step 3. Since the amount of excessive oxygen decreases with Sr doping, for the end members with little oxygen hyper-stoichiometry like Sr40, oxygen vacancies in perovskite layer might also come to play as active sites. Therefore, besides through interstitial insertion, the incorporation step can proceed via the lattice oxygen vacancies as shown in step 3' as well.

It needs to be mentioned that in the reaction order derivation, the activity of interstitial oxygen in step 3 is taken to be independent to $P_{\mathrm{O} 2}$ for simplicity, which in fact changes more or less with $P_{\mathrm{O} 2}$ in those lanthanum nickelates. However, how to formulate this effect into the reaction order equations has not been addressed in literature so far. We tentatively believe that one solution could be using the $\mathrm{O}_{2}$-dependent form of the activity for $\mathrm{O}_{\mathrm{i}}^{\prime \prime}$, and meanwhile separating the total overpotential into different parts consumed by 
surface exchange $\left(\Delta E_{1}\right)$, bulk diffusion $\left(\Delta E_{2}\right)$ and interface exchange $\left(\Delta E_{3}\right)$ respectively, in order to meet the Nernst equation $E=E_{0}+\frac{\mathrm{RT}}{4 \mathrm{~F}} \ln P_{\mathrm{O} 2}$ for the overall reaction. As $\Delta E_{1} \leq \Delta E$ in magnitude, the dependency on $P_{\mathrm{O} 2}$ from potential activation effect is actually less than 1/8. After adding the $1 / 6 \mathrm{O}_{2}$-dependency for $\mathrm{O}_{\mathrm{i}}^{\prime \prime}$ into it in step 3, the net reaction order, 7/24 in maximum, is still much less than $1 / 2$. As for step 3', since the activity of $O_{0}^{\times}$shows a negative dependence on $P_{\mathrm{O} 2}$, the reaction order is actually less than $1 / 8$. It is thus clear that among those four steps the surface dissociative adsorption is the main contribution in the surface exchange process.

Oxygen adsorption in perovskites is generally believed to be facilitated by the interaction between oxygen molecule and the transition metal at B site.[66] The importance of the transition metal would also largely retain in the $\mathrm{K}_{2} \mathrm{NiF}_{4}$ structure given the nearest surrounding of such element is the same as that in perovskite. For example, the surface exchange rate of LNO is found to increase about 1 order of magnitude after $10 \%$ Co substitution of $\mathrm{Ni}$, accompanied by a largely decreased activation energy,[67] suggesting the dissociative adsorption ability of the $\mathrm{A}_{2} \mathrm{BO}_{4+\delta}$ structure heavily depends on the nature of $\mathrm{B}$ site element. For lanthanum nickelates, the charge compensation for $\mathrm{Sr}$ doping is realized by loss of interstitial oxygen and oxidation of $\mathrm{Ni}^{2+} \cdot[27,37]$ Increased oxidation state from $\mathrm{Ni}^{2+}$ to $\mathrm{Ni}^{3+}$ as well as the resultant increased oxygen adsorption energy as $\mathrm{Sr}$ doping is reported recently by Lee et al. in the thin film $(\mathrm{LaSr})_{2} \mathrm{NiO}_{4+\delta}$ study.[68] The surface exchange rate is found to decrease with Sr. It hence can be concluded that Sr doping diminishes the surface dissociative adsorption activity by increase the oxidation state of $\mathrm{Ni}$.

The fact that dissociative adsorption process is the main contribution to the surface exchange resistance cannot preclude the possibility of influence from other elementary step. Anisotropic kinetics is observed on surface exchange for such materials in a few of studies as mentioned above. However, among those elementary steps, the incorporation process could be most different along a-axis (100) compared to c-axis (001), since adsorption is processed by the same $\mathrm{Ni}$ ions in both cases. It implies that although the incorporation process in a-b plane is truly much faster than that proceeding along c-axis, it could be no faster than other elementary steps in some cases; otherwise the rate for the overall reaction cannot be substantially altered by changing surface orientation. Such incorporation in a-b 
plane displayed in step 3 is related directly to the activity of $\mathrm{O}_{\mathrm{i}}^{\prime \prime}$ which in turn is largely determined by Sr doping. As a result, Sr doping would likely affect the incorporation process also. As we can see, the reaction orders in Fig. 6a and b increase with temperature for LNO and Sr10. Because the interstitial oxygen is more sensitive to $P_{\mathrm{O} 2}$ at higher temperature, $[38,40]$ these trends can probably imply the involvement of resistance from incorporation process in the overall polarization resistance. One the other hand, reaction order for Sr30 in Fig. 6d shows small changes, or even decreases in Fig. 6e for Sr40 with increasing temperature, possibly meaning the $\mathrm{O}_{\mathrm{o}}^{\times}$starts to work in such process.

To more clearly unveil the mechanism on surface exchange, cathode with simpler microstructure is preferred. In the present porous structure, the bulk contribution in the colimiting situation is comparative to surface process, and variation of $P_{\mathrm{O} 2}$ will not only change the activity of adsorbents but also the actual active reaction zone. Those factors will more or less affect the accuracy of reaction order judgment. A dense and thin cathode deposited on electrolyte will be able to bypass those issues, since the contribution from bulk is literally controlled by the cathode thickness and the surface exchange area is unchangeable with $P_{\mathrm{O} 2}$ and temperature. The experimental study on the dense cathode is undergoing currently in our group and will be presented in the near future.

\subsection{Summary}

In this chapter, the effect of Sr doping on electrode performance and ORR kinetics of LNO R-P phase has been investigated. The best performance was obtained with the undoped material, and Sr doping increased the polarization resistance. The surface exchange and bulk/surface diffusion co-controlling situation is observed. Significant bulk active lengths are confirmed through the chemical capacitance, 3.9 and $3.4 \mu \mathrm{m}$ for LNO and Sr10 at $600^{\circ} \mathrm{C}$, respectively, indicating the importance of bulk diffusion contribution in determining the electrode performance. On the other hand, for the surface exchange reaction, oxygen dissociative adsorption is suggested to be the primary elementary step meditating the exchange kinetics. The impaired adsorption ability after Sr doping is associated to the increased oxidation state of $\mathrm{Ni}$. 


\section{Chapter 4: Investigation of surface exchange kinetics on dense symmetrical cells}

From our previous EIS results regarding porous Sr-doped LNO cathode, it is hard to associate the resistance from EIS directly to each ORR elementary processes because of the difficulty in describing the microstructure of the porous electrode. The dense electrode configuration was adopted in this chapter even though in practice porous electrode is chosen over the dense electrode. By using the dense electrode, the surface area, the thickness of electrode, the interface between electrode and electrolyte and lastly the 3PB are theoretically well-defined. Through this method, there is a good chance to distinguish the contribution from surface exchange, ionic and electronic bulk transport and ion interface exchange.

As bulk characterization has been documented by co-workers with less controversy compared to the surface process, this chapter is devoted to the surface kinetics investigation of LSNO on symmetric cells with simple geometry. Dense electrode layers in thickness of $\sim 40 \mu \mathrm{m}$ are fabricated successfully using a novel spray-modified pressing method. Negligible bulk diffusion resistance is confirmed by both parallel experiment and EIS analysis, resulting in exclusive focus on the surface process. The performance characterization is carried out in various $P_{\mathrm{O} 2}$ atmospheres. It is ambiguously proved that $\mathrm{Sr}$ doping impairs the surface kinetics of lanthanum nickelates. The corresponding rate determining step is discussed base on the reaction orders. The interstitial oxygen is suggested to be the key role when the oxygen incorporation is rat determining. For the first time, a physical model is proposed to illustrate how those interstitial species work to regulate the exchange rate of the incorporation reaction. It is noteworthy that through the present study the spray-modified pressing route exhibits its handiness and reliability, then the potential capability in the surface kinetics investigations of electrode materials. 


\subsection{Chemical stability with LSGM and microstructure of LSNO thin layers}

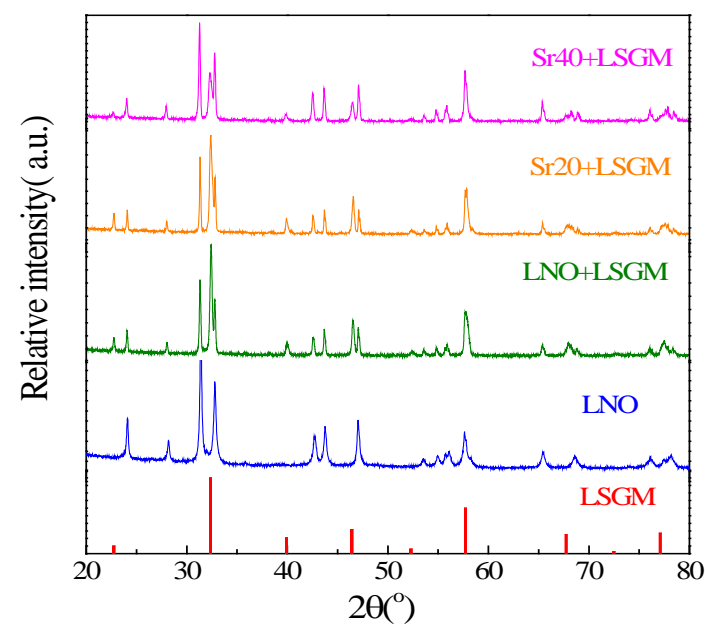

Fig.4 .1 XRD for LSNO/LSGM mixtures heated at $1300^{\circ} \mathrm{C}$.

Since the air-sprayed LSNO layers were co-sintered with LSGM at $1300^{\circ} \mathrm{C}$, the chemical compatibility is examined first. Fig. 4.1 shows the XRD of LSNO/LSGM mixture after heated to $1300^{\circ} \mathrm{C}$. XRD for LNO sharing the same pattern with Sr doped samples is provided as baseline. No foreign peaks are observed in those spectra for all mixtures.
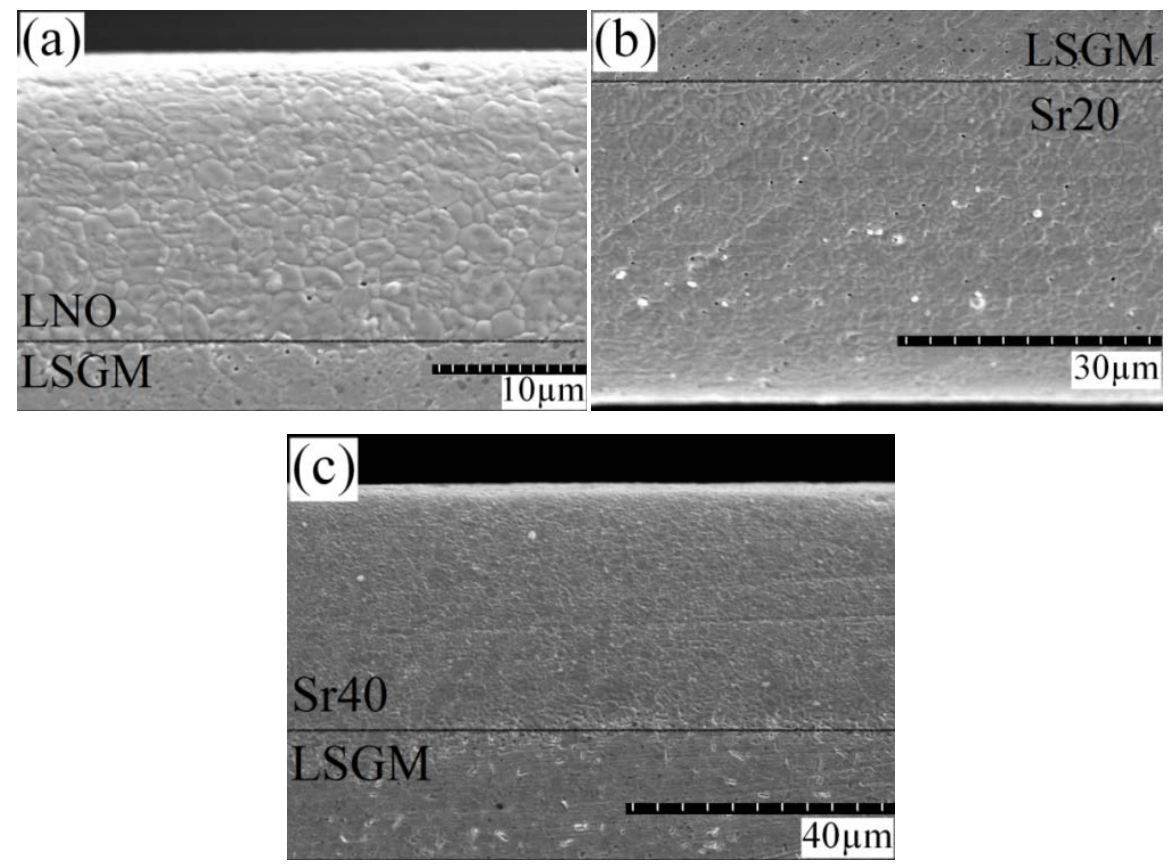

Fig. 4.2 Cross-sectional SEM for LSNO thin layers. 
Fig. 4.2 displays the morphology of the LSNO thin layers. The cross section of post-test samples was polished and thermally etched at $1200^{\circ} \mathrm{C}$ for $4 \mathrm{~h}$ before SEM observation. All thin layers are successfully densified and the adhesion between LSGM and LSNO is very good in each sample. With close inspection, no impurity at the interface is found, consistent with the XRD results and proving good chemical stability between LSNO and LSGM.

\subsection{Surface-dominant situation on the well-defined R-P cathodes}

In our experiment, it was found that polarization resistances from dense electrode samples in the same batch using silver paste as current collector varies 2 5 times in magnitude, because silver paste on the dense electrode specimens may partially block the surface or work as extra catalyst. Bare LSNO surface is actually the most desirable configuration to credibly characterize the ORR kinetics if the sheet resistance allows. For the bare surface samples in this study, the sheet resistance is calculated to be $0.07 \Omega$, assuming $\sigma_{\mathrm{e}}=100 \mathrm{~S} / \mathrm{cm}$, layer thickness of $50 \mu \mathrm{m}$. Such value is marginal even compared with the smallest $R_{\mathrm{p}}$ (absolute value of $3.7 \Omega$ as will be shown below), therefore allowing no current collector being applied in the EIS measurement.

Table 4-1. Summary of $R_{\text {surf }}$ from different cells measured in air at various temperatures and the related relative standard deviation (RSD).

\begin{tabular}{|c|c|c|c|c|c|c|c|c|c|c|c|c|}
\hline \multirow[b]{3}{*}{$T\left({ }^{\circ} \mathrm{C}\right)$} & \multicolumn{3}{|c|}{ LNO } & & \multicolumn{3}{|c|}{ Sr20 } & \multicolumn{5}{|c|}{ Sr40 } \\
\hline & $\begin{array}{c}\text { Cell-1 } \\
(38 \mu \mathrm{m})\end{array}$ & $\begin{array}{c}\text { Cell-2 } \\
(20 \mu \mathrm{m})\end{array}$ & $\begin{array}{l}\text { Cell-3 } \\
(8 \mu \mathrm{m})\end{array}$ & & $\begin{array}{c}\text { Cell-1 } \\
(19 \mu \mathrm{m})\end{array}$ & $\begin{array}{c}\text { Cell-2 } \\
(38 \mu \mathrm{m})\end{array}$ & $\begin{array}{c}\text { Cell-3 } \\
(49 \mu \mathrm{m})\end{array}$ & & $\begin{array}{c}\text { Cell-1 } \\
(30 \mu \mathrm{m})\end{array}$ & $\begin{array}{c}\text { Cell-2 } \\
(40 \mu \mathrm{m})\end{array}$ & $\begin{array}{c}\text { Cell-3 } \\
(18 \mu \mathrm{m})\end{array}$ & \\
\hline & & $R_{\mathrm{p}}\left(\Omega \mathrm{cm}^{2}\right)$ & & \%RSD & & $R_{\mathrm{p}}\left(\Omega \mathrm{cm}^{2}\right.$ & & \%RSD & & $R_{\mathrm{p}}\left(\Omega \mathrm{cm}^{2}\right)$ & & \%RSD \\
\hline 600 & 41 & 33.6 & 52.1 & 22 & 116 & 135 & 122.6 & 7.7 & -- & -- & -- & -- \\
\hline 650 & 16.2 & 15 & 18.3 & 10.1 & 39.9 & 47.6 & 49.2 & 10.9 & 103.2 & 99.4 & 112.7 & 6.5 \\
\hline 700 & 7.9 & 7.1 & 8.2 & 7.4 & 21 & 23.1 & 24.8 & 8.3 & 34.6 & 36.4 & 39.9 & 7.3 \\
\hline 750 & 4.4 & 4.2 & 5.3 & 12.6 & 11.9 & 12.9 & 13.6 & 6.7 & 17.4 & 19.6 & 21.2 & 9.8 \\
\hline 800 & 2.6 & 2.7 & 3.0 & 7.5 & 6.9 & 7.8 & 8.1 & 8.2 & 9.5 & 10.4 & 10.8 & 6.5 \\
\hline
\end{tabular}

The reproducibility of so-called spray-modified pressing method is examined to ensure genuine evaluation on those candidates. Three cells of each kind were made and 
measured, each with a different electrode thickness. $R_{\mathrm{p}}$ and the relative standard deviation (RSD) are summarized in Table 4-1. RSD as such are generally much smaller than those from the porous electrodes. The statistical error around $10 \%$ is well acceptable provided that performance discrepancy is $\sim 200 \%$ between LNO and Sr20, 60\% between Sr20 and Sr40, confirming the reliability of this sample fabrication procedure and the following measurement. In addition, from this table, no systematic correlation between $R_{\mathrm{p}}$ and the layer thickness can be drawn, indicating negligible contribution from bulk diffusion. Also, the important speculation in our prior study that Sr doping brings detrimental effect to the surface kinetics is unambiguously proven in this table.

(a)

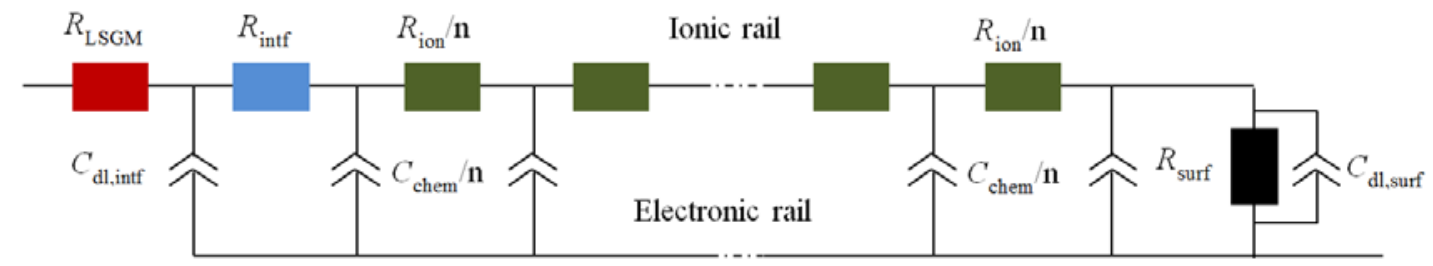

(b)

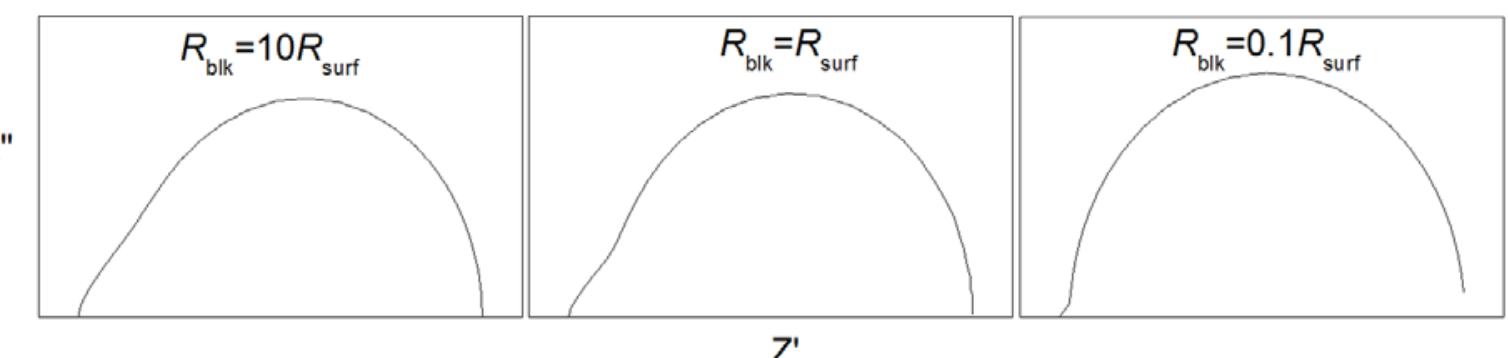

(c)

$C_{\text {chem }}$

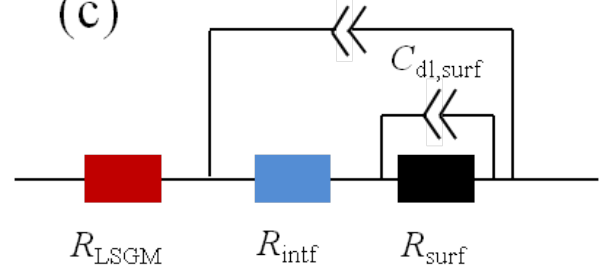

Fig. 4.3 (a) The equivalent circuit for LSNO dense electrode with electronic rail blocked by the LSGM, derived from Ref....The electronic resistance is omitted due to its far higher conductivity than ionic rail. $R_{\text {ion }}$ and $C_{\text {chem }}$ refer to the overall values from the dense layer, and both are weighted by $1 / \mathrm{n}$ with $\mathrm{n}$ being the number of units in the transmission model.

(b) EIS profiles simulated by Z-view using the circuit in (a) with $R_{\mathrm{LSGM}}$ and $R_{\text {intf }}$ shortcircuited in view of brevity, $C_{\mathrm{chem}}=1000 C_{\mathrm{dl} \text {,surf. }}$ Three scenarios are carried out under a 
fixed total resistance with different portions from the bulk and surface: $R_{\mathrm{blk}}=10 R_{\text {surf, }}$ $R_{\mathrm{blk}}=R_{\text {surf, }} R_{\mathrm{blk}}=0.1 R_{\text {surf. }}$ (c) The simplified circuit for the surface-dominant case.

The EIS features are interpreted to verify the designed surface-control situation from another aspect. The resistive/capacitive behavior of surface reaction, bulk diffusion as well as interface exchange in those LSNO samples can be mapped into an equivalent circuit as shown in Fig. 4.3a on the basis of the theoretical impedance treatment of MIEC materials by Jamnik et al.[69, 70] In this model, two rails conduct different charge carriers throughout the dense layer. The electronic rail is finally blocked by LSGM at the interface. $R_{\text {ion }}$ and $C_{\text {chem }}$ refer to the total ionic resistance and chemical capacitance of the thin layer, respectively. Being proportional with the volume of LSNO, $C_{\text {chem }}$ can be considerably larger than the double layer capacity in interfaces. For the sake of directness, the relative importance of bulk diffusion and surface reaction is simulated by Z-view under three representative scenarios: bulk dominant as $R_{\mathrm{blk}}=10 R_{\text {surf, }}$ equal contribution as $R_{\mathrm{blk}}=R_{\text {surf, }}$ surface dominant as $R_{\mathrm{blk}}=0.1 R_{\text {surf. }} \cdot C_{\text {chem }}$ f $400 \sim 800 \mathrm{~F} / \mathrm{cm}^{3}$ for LSNO (shown later in Fig. 4.6) yields $1 \sim 2 \mathrm{~F} / \mathrm{cm}^{2}$ in area specific values for dense electrodes $20 \sim 50 \mu \mathrm{m}$ in thickness. In this regard, $C_{\text {chem }}$ is set 1000 times $C_{\mathrm{dl}}$, surf in the simulation, $C_{\mathrm{dl}}$, surf being the surface double layer capacitance with a typical value of $\sim 1 \mathrm{mF} / \mathrm{cm}^{2}$. The results are displayed in Fig. 4.3b ( $R_{\mathrm{LSGM}}$ and $R_{\text {intf }}$ are omitted for brevity). In fact, it is found that those spectra profiles are

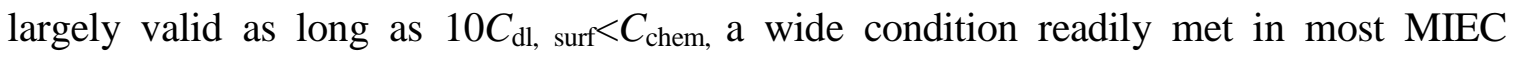
electrode materials. As shown in Fig. 4.3b, in the bulk dominant case the spectrum features a distinguished near straight line response at the high frequency $(\mathrm{HF})$ region, which is perfectly consistent with the bulk $\mathrm{O}^{2-}$ diffusion limit modeled by Adler for MIEC electrodes. In the equal contribution case, such HF feature is still distinct though less prominent. In the surface dominant situation, the spectrum is mostly controlled by a semicircle due to the surface reaction. For the last case, the equivalent circuit can be simplified as Fig. 4.3c given $R_{\text {ion }}$ and $C_{\text {dl, surf }}$ are much smaller than $R_{\text {surf }}$ and $C_{\text {chem, }}$ respectively. In this simplified circuit, a two-arc EIS profile can be anticipated when the characteristic frequencies differ. 

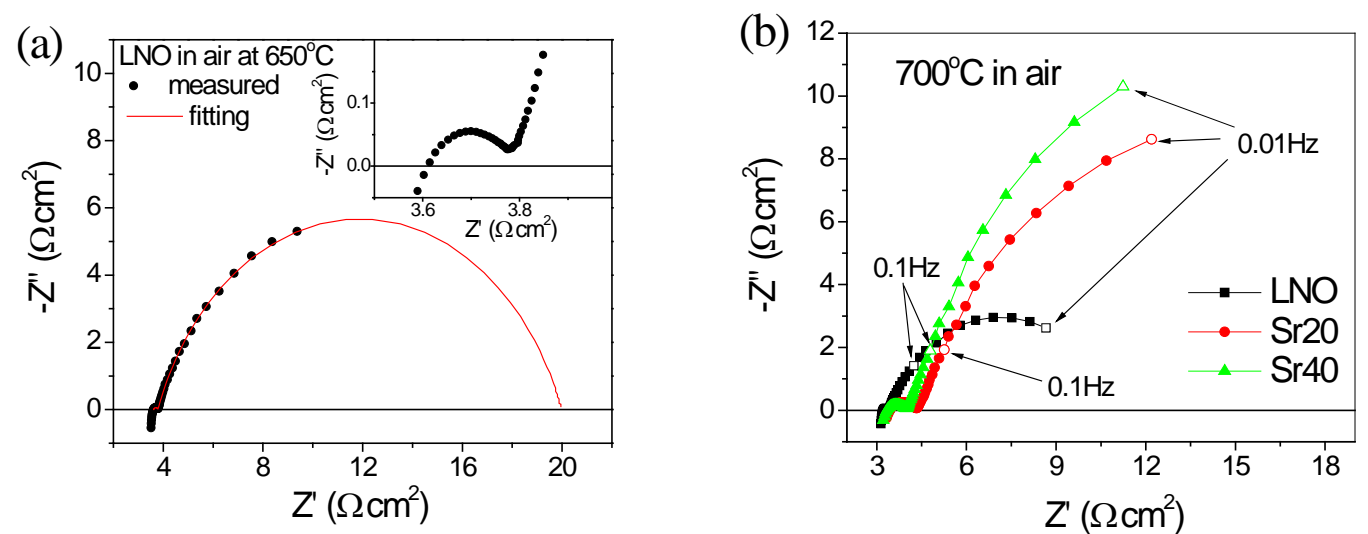

Fig. 4.4 (a) Measured and fitted surface-dominant spectrum of LNO, and (b) comparison of EIS profiles for LNO, Sr20 and Sr40 at $700^{\circ} \mathrm{C}$ in air.

Fig. 4.4a shows the impedance for LNO measured in air at $650^{\circ} \mathrm{C}$. Two arcs can be clearly observed after zooming in the HF arc in the insert. Such spectrum coincides with the last case only in Fig. 4.3b, confirming the surface-control judgment. This result is quite rational, considering that the critical length of LNO marking comparable contributions from surface and bulk is 500 1000 $\mu \mathrm{m}$, much bigger than the LNO thin layer here. As such, the spectrum is fitted into the simplified circuit in Fig. 4.3c. A very satisfactory fitting is displayed in Fig. 4.4a.

The HF axis intercept is $3.6 \Omega \mathrm{cm}^{2}$, in reason able agreement with the resistance predicted on LSGM electrolyte $1.4 \mathrm{~mm}$ in thickness at $650^{\circ} \mathrm{C}\left(3.3 \Omega \mathrm{cm}^{2}\right.$ after normalized). Such value will be affected if chemical reaction in LSGM/LSNO interface occurs. The HF small arc of $0.18 \Omega \mathrm{cm}^{2}$ at $3000 \mathrm{~Hz}$ is assigned to the oxygen transfer resistance in the light of observations from similar thin film electrode investigations.[54] Such resistance is reported to depend on the ionic conductivities of the components at interface, and consequently would be sensitive to the interfacial impurity here. Therefore, in addition to $\mathrm{XRD}$ and SEM results, the absence of anomalous resistances in the spectra corroborates the chemical stability between LSGM/LSNO as well. Fig. 4.4b shows the EIS profiles including Sr20 and Sr40. All specimens display similar semicircle-dominant feature, meaning that the surface-control situation is valid in all samples. 


\subsection{Surface exchange kinetics of LSNO}

The specimens with intermediate resistance in each kind are chosen to study the underlying mechanism of Sr doping. The equivalent $k$ values can be derived from the impedance according to Eq. 4-1,[71, 72]

$$
k^{q}=\frac{R T}{4 F^{2} R_{\text {surf }} c_{\mathrm{o}}}
$$

Where $F$ is the Faraday's constant, $c_{0}$ the oxygen concentration of LSNO, $R$ and $T$ remain the usual physical meanings. Displayed in Fig. 4.5 are $k^{\mathrm{q}}$ calculated from the impedance. $k^{\mathrm{q}}$ is $1.63 \times 10^{-7} \mathrm{~cm} / \mathrm{s}$ for LNO at $600^{\circ} \mathrm{C}$, in reasonable agreement with $\sim 2 \times 10^{-7}$ $\mathrm{cm} / \mathrm{s}$ for polycrystalline thin film LNO at $587^{\circ} \mathrm{C}$ reported by Kim et al. At the intermediate temperature $700^{\circ} \mathrm{C}, k^{\mathrm{q}}$ is $8.59 \times 10^{-7} \mathrm{~cm} / \mathrm{s}$ for LNO and decreases to $2.65 \times 10^{-7}, 1.68 \times 10^{-7}$ $\mathrm{cm} / \mathrm{s}$ for Sr20 and Sr40, respectively. The activation energies are fitted from those Arrhenius curves. $E_{\mathrm{a}}$ in $1 \sim 1.3 \mathrm{eV}$ have been assigned to the surface exchange process of lanthanum nickelates in the studies by skinner et al, consistent with the present surface reaction dominant situation. For each sample, $E_{\mathrm{a}}$ decreases with increasing temperature. Such trend can be expected, assuming two or more processes with different $E_{\mathrm{a}}$ are involved in the overall reaction, because the process with higher $E_{\mathrm{a}}$ will naturally be outweighed by the one with lower value as temperature increases.

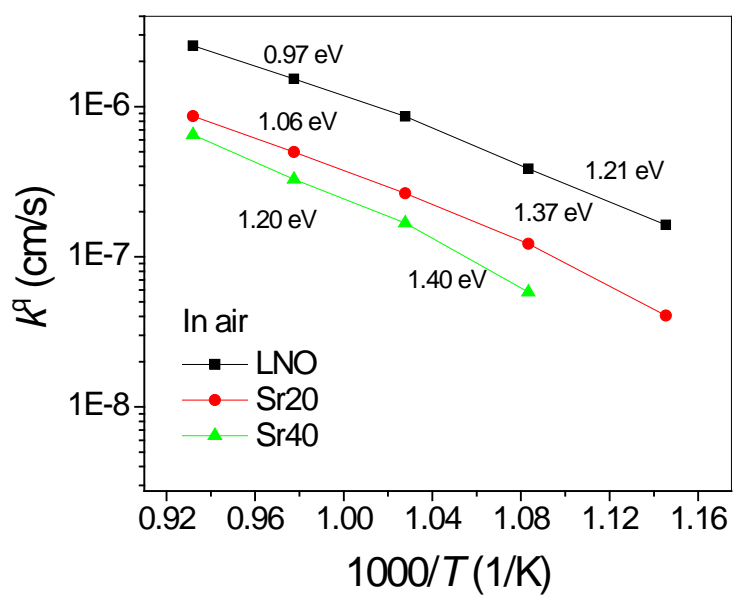

Fig. 4.5 Temperature-dependency of $k^{\mathrm{q}}$ and $E_{\mathrm{a}}$. 
Fig. 4.6 shows the volume specific capacitances derived from the semicircles. $C_{\text {chem }}$ is reduced upon Sr doping. In addition, when lowering $P_{\mathrm{O} 2}$ it decreases in LNO, but almost remains the same for the doped samples. The same phenomena are reported in our previous porous LSNO study. As $C_{\text {chem }}$ is related to the concentration of interstitial oxygen $\left(\mathrm{O}_{\mathrm{i}}^{\prime \prime}\right.$ in Kröger-Vink notation), it was once used to determine the relevance between the catalytic activity and the amount of $\mathrm{O}_{\mathrm{i}}^{\prime \prime}$. However, no uniform correlation between $C_{\text {chem }}$ and the electrode performance (as shown in Fig. 4.5 and Fig. 4.7) can be established herein so as to explain the effect of Sr doping and the influence of $P_{\mathrm{O} 2}$ change at the same time. The lack of certain connection challenges the prior supposition in literature, but is not difficult for one to agree to after checking the meaning of $C_{\text {chem }}$ carefully. In the electrode with welldefined geometry, $C_{\text {chem }}$ is solely determined by the thermodynamic factor $(f),[55]$

$$
\begin{gathered}
C_{\text {chem }}=\frac{16 F^{2}}{R T V_{\mathrm{m}} f} \\
f=\frac{1}{2} \frac{\partial \ln P_{\mathrm{O} 2}}{\partial \ln (4+\delta)}
\end{gathered}
$$

where $V_{\mathrm{m}}$ is the molar volume of LSNO $\left(\sim 113 \mathrm{~cm}^{3} / \mathrm{mol}\right), \delta$ the oxygen hyperstoichiometry.

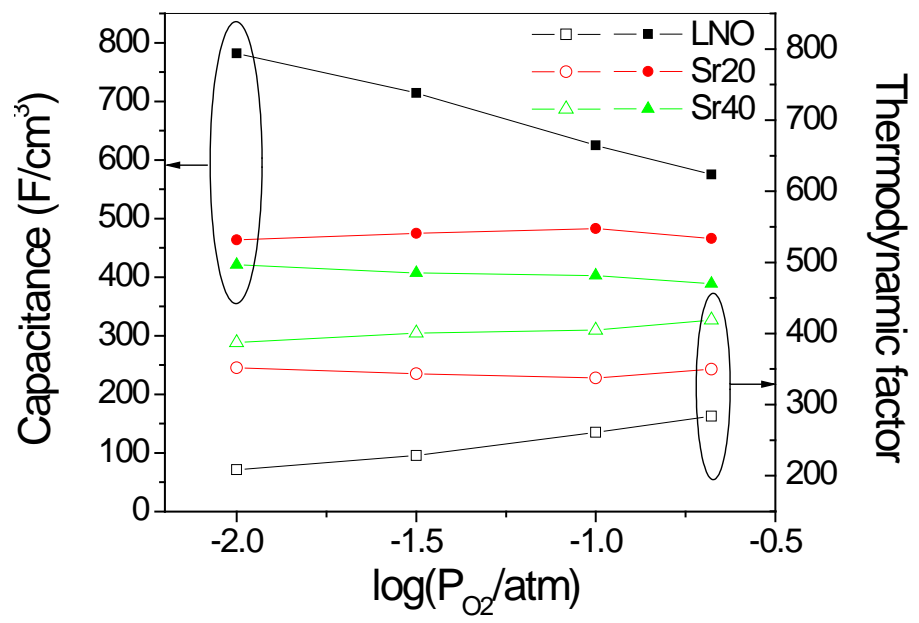

Fig. 4.6 Variation of $C_{\text {chem }}$ and $f$ towards $P_{\mathrm{O} 2}$ at $700^{\circ} \mathrm{C}$. 
As formulated by Eq. 4-2 and 4-3, although $C_{\text {chem }}$ is related to $\mathrm{O}_{\mathrm{i}}^{\prime \prime}$, what it describes directly is the willingness of change in oxygen stoichiometry, instead of the amount of $\mathrm{O}_{\mathrm{i}}^{\prime \prime}$. Truly, only the variation of $\mathrm{O}_{\mathrm{i}}^{\prime \prime}$ can be derived from $C_{\text {chem }}$ through $f$. Rearranging Eq. 3gives,

$$
f=\frac{1}{2} \frac{\partial \ln P_{\mathrm{O} 2}}{\partial \ln (4+\delta)}=\frac{4+\delta}{2 \delta} \frac{\partial \ln P_{\mathrm{O} 2}}{\partial \ln \delta}
$$

Integrating Eq. 4 yields,

$$
\delta=\delta_{0} P_{\mathrm{O} 2}^{\frac{4+\delta}{2 \delta f}}, \text { or } \delta \propto P_{\mathrm{O} 2}^{\frac{4+\delta}{2 \delta f}}
$$

The $P_{\mathrm{O} 2}$ dependency of $\delta$ is then estimated as $\delta \propto P_{\mathrm{O} 2}^{\frac{1}{22}}$ at $P_{\mathrm{O} 2}$ near air, assuming $\delta \approx 0.15$. For the doped samples, it becomes complicated. At heavier doping level $\mathrm{O}_{\mathrm{i}}^{\prime \prime}$ could be depleted where as the oxygen vacancy in the perovskite layers is created. Such fact seems to dispute the validity of Eq. 4-3 in which $\mathrm{O}_{\mathrm{i}}^{\prime \prime}$ is formally assumed as the primary defect, because the capacity effect also comes from the change of $V_{o}^{*}$ content. However, the capacity behavior originates from the accumulation/depletion of negative charges in form of oxygen ions in the materials (accompanied by the compensating change of electronic defects). All oxygen ions equally add to $C_{\text {chem }}$ regardless whether in the form of interstitial or lattice oxygen. As a result, Eq. 4-3 is complete in expressing the correlation between $C_{\text {chem }}$ and oxygen content since the total nonstoichiometric oxygen is rightfully represented by $\delta$. If assuming $\delta \approx 0.07$ for $\operatorname{Sr} 20$ and 0.05 for $\mathrm{Sr} 40$ according to Vashook et al, $P_{\mathrm{O} 2}$ dependency can be determined as $\delta \propto P_{\mathrm{O} 2}^{\frac{1}{13}}$ for the former and $\delta \propto P_{\mathrm{O} 2}^{\frac{1}{11}}$ for the latter based on those $C_{\text {chem. }}$. It can be seen at last that no simple linear conversion between $C_{\text {chem }}$ and $\mathrm{O}_{\mathrm{i}}^{\prime \prime}$ exists, therefore one cannot rule out the role of $\mathrm{O}_{\mathrm{i}}^{\prime \prime}$ in electrode performance based on $C_{\text {chem }}$.

The reaction orders $(n)$ of $R_{\text {surf }}$ towards $P_{\mathrm{O} 2}$ in the form of $1 / R \propto P_{\mathrm{O} 2}^{n}$ are displayed in Fig. 4.7. After eliminating bulk influence, the reaction orders in Fig. 4.7 are more strictly representative of ORR. $n$ for all specimens are nearly 0.5 , suggesting the same limiting 
step(s) for all samples regardless of Sr doping. In comparison to the previous results, it is reasonable to find that those reaction orders for dense layer samples are generally larger than obtained from the surface/bulk co-control porous samples since bulk resistance usually yields smaller $P_{\mathrm{O} 2}$ dependency. The elementary steps in ORR are listed as below. One single step cannot account for the results in Fig. 4.7. The involvement of multiple processes is implied by the changing $E_{\text {a }}$ presented in Fig. 4.5 as well. The assignment of RDS to the oxygen dissociative adsorption and ion incorporation was proposed in the last work based on the detailed analysis regarding $n$ values and basic findings in literature, and is corroborated here by those newly obtained reaction orders.

$\begin{array}{lcc}\text { Step 1 } & \mathrm{O}_{2} \leftrightarrow 2 \mathrm{O}_{\text {ads }} & \mathrm{n}=1 \\ \text { Step 2 } & \mathrm{O}_{\text {ads }}+\mathrm{e} \leftrightarrow \mathrm{O}_{\text {ads }}^{-} & \mathrm{n}=3 / 8 \\ \text { Step 3 } & \mathrm{O}_{\text {ads }}^{-}+\mathrm{e}+\mathrm{V}_{\mathrm{i}}^{\times} \leftrightarrow \mathrm{O}_{\mathrm{i}}^{\prime \prime} & \mathrm{n}=1 / 8 \\ \text { Step 3' } & \mathrm{O}_{\text {ads }}^{-}+\mathrm{e}+\mathrm{V}_{\mathrm{o}}^{*} \leftrightarrow \mathrm{O}_{\mathrm{o}}^{\times} & \mathrm{n}=1 / 8\end{array}$
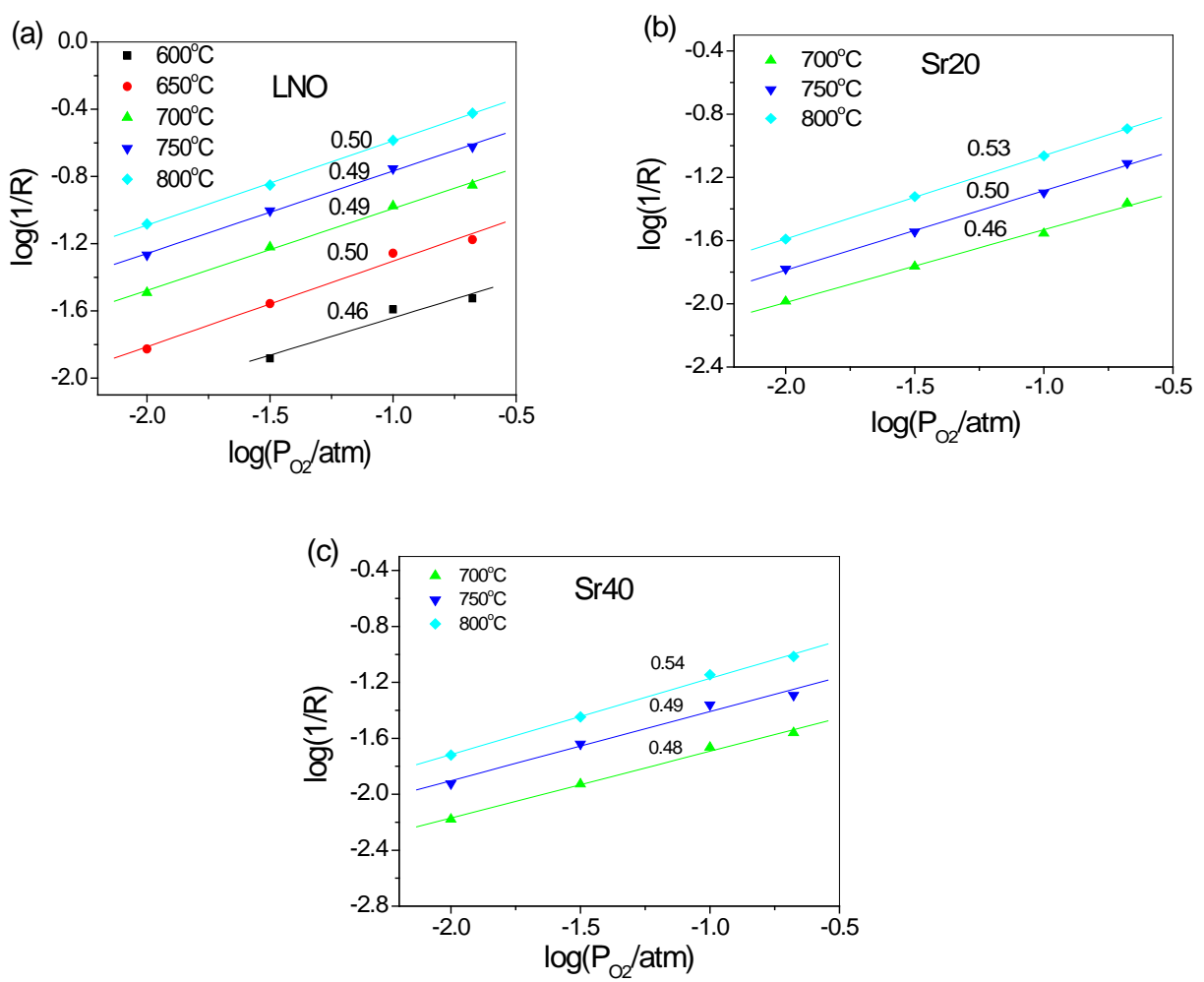

Fig. 4.7 $P_{\mathrm{O} 2}$-dependent resistances for LNO (a), Sr20 (b) and Sr40 (c). 
While reaction order to identify RDS has been prevalent in EIS studies, several remarks concerning the limitation of such approach might be noteworthy. In the original deviation founded on the mass action law, several assumptions are taken to simplify the complexity of the real case or make it physically achievable. For instance, a) low surface coverage in Langmuir isothermal adsorption is assumed to yield a linear relationship between adsorbents and $P_{\mathrm{O} 2}$, like in step 1; b) the inventory of oxygen defects in the electrode is assumed constant, like in step 3 and 3'; c) the activity of electronic defects is assumed to be subject only to the electrochemical potential difference in the form of $\exp \left(\frac{ \pm F}{2 R T} \Delta E\right)$ (if taking reaction symmetry factor as $\left.1 / 2\right)$ between two phases, such as surface/electrode, or electrode/electrolyte. While those assumptions are largely justifiable for noble metal electrode, like $\mathrm{Pt}$, or oxides stable in a wide $P_{\mathrm{O} 2}$ range, like LSM, some of them may not be sound in some extent for materials with variable stoichiometry, such as LNO at the present case. Firstly, for assumption b), as estimated from $C_{\text {chem }}$ in Fig. 4.6, the oxygen hyperstoichiometry in LSNO shows dependency on $P_{\mathrm{O} 2}$. Although not big, it adds complexity to the accurate judgment. In principle, what's more important is how to take account of this influence theoretically into the equations is not clear so far. A possible solution mentioned in our last work is to divide the total overpotential into small parts associated with individual reactions, in order to reconcile the contradiction in the Nernst relationship between electrode potential $E$ and $P_{\mathrm{O} 2}$ (leaving the form of $E$ the same but replacing the constant activity ofO $\mathrm{i}_{\mathrm{i}}^{\prime \prime}$ with $\delta \propto P_{\mathrm{O} 2}^{\frac{1}{22}}$ yields a contradictory result $E=E_{0}+$ $\left.\frac{11 R T}{48 F} \ln P_{\mathrm{O} 2}\right)$. Division of the overpotential based on the specific surroundings for each reaction such as two-phase boundary (2PB), or three-phase boundary (3PB) reactions ( $\left.\Delta E_{2 \mathrm{~PB}}, \Delta E_{3 \mathrm{~PB}}\right)$ will of course add more sense to the physical picture of the reality, but seems still inadequate, considering at last a material-specific property will be expressed by an universal formula applicable to anything. Secondly, for the activity of electrons in assumption c), from the viewpoint of free energy change, the electrode potential $E$ indeed correctly describes the energy status of this species in the forward/backward reaction, and also embrace the concentration effect of available electrons with Boltzmann distribution (changing the energy level other than the total amount), but it has nothing to do with the inventory change of electrons triggered by $P_{\mathrm{O} 2}$ (changing the total amount). Leaving out 
such $P_{\mathrm{O} 2}$ dependence of concentration in the rate equation is virtually equivalent as taking the concentration as constant over the $P_{\mathrm{O} 2}$ range studied, which is acceptable for metal electrode but not valid for oxides experiencing remarkable fluctuation in the electron population upon $P_{\mathrm{O} 2}$ variation. For instance, through managing Fe amount in $\mathrm{Sr}(\mathrm{TiFe}) \mathrm{O}_{3}$ to adjust the Fermi level and the resultant concentration of active electrons, Jung et al. concluded that the reaction rate is governed by the density of electrons in the conduction band,[73] corroborating the importance of the quantity of electron in the reaction kinetics. Back to the present case, upon $P_{\mathrm{O} 2}$ change the amount of electronic defects in LSNO is found to alter in a large extent as can be seen from the average valence of $\mathrm{Ni}$ or from the See beck coefficient results, casting extra contribution to the overall $P_{\mathrm{O} 2}$ dependence for the charge transfer steps. In view of those concerns, it might be wise of one to use the reaction orders in Eq. (4-6)-(4-9) as a loose guide, and meanwhile seek further evidence from other physical phenomena, such as, the similar decreasing trend of $k$ and Don Sr doping, the changing $E_{\mathrm{a}}$ towards varying temperature in Fig. 4.5 and the anisotropic properties of LNO witnessed in literature and etc. As an example, considering the common trend between $D$ and $k$, it is rational to view the amount of $\mathrm{O}_{\mathrm{i}}^{\prime \prime}$ in LSNO as a key role, which in turn favors step 3 being rate-determining. This speculation has already been addressed briefly in the prior study. But specifically how such species works to mediate the surface kinetics is technically missing thus is presented in more details in below.

\subsection{The role of $O_{i}^{\prime \prime}$ in the incorporation reaction of $R-P$ phase}

A similar trend between $D$ and $k$ in perovskites has been reported. After collecting a number of results from independent sources, Kilner et al. derived an expression for $k$ in terms of bulk atomistic parameters.[74] Conceptually, the surface exchange reaction

includes all subsequent steps until the mass transfer finishes in the gas/solid interface, which is different from the bulk transport that occurs in a single phase. The sole factor involved into both processes is $\mathrm{V}_{\mathrm{o}}^{*}$. Therefore by assuming $\mathrm{V}_{\mathrm{o}}^{*}$ to act a major role in the surface exchange process, the relationship between $D$ and $k$ was established in perovskites.[74-77] Likewise, it appears rightful for one to explain the $D \& k$ correlation in LSNO by similarly stressingO $\mathrm{O}_{\mathrm{i}}^{\prime \prime}$. But comparing the defects in perovskites and R-P phase, 
an immediate question coming up is how two opposite species, $\mathrm{V}_{\mathrm{O}}^{\prime \prime}$ and $\mathrm{O}_{\mathrm{i}}^{\prime \prime}$, can play similar roles in the incorporation process, because only vacancies regardless in lattice or in interstice are the active sites in such reaction. In the following, a relationship between $k$ and $\mathrm{O}_{\mathrm{i}}^{\prime \prime}$ is proposed, by which the seemingly contrary roles of $\mathrm{V}_{\mathrm{O}}^{\prime \prime}$ in perovskite and $\mathrm{O}_{\mathrm{i}}^{\prime \prime}$ in R-P structure could be harmonized in principle.

Within the law of mass action, the reaction rate for step 3 is,

$$
r_{3}=k_{3}\left[\mathrm{O}_{\mathrm{ads}}^{-}\right]\left[\mathrm{V}_{\mathrm{i}}^{\times}\right] \exp \left(-\frac{\Delta E_{2 \mathrm{~PB} F}}{2 R T}\right)-k_{3}^{-}\left[\mathrm{O}_{\mathrm{i}}^{\prime \prime}\right] \exp \left(\frac{\Delta E_{2 \mathrm{~PB} F}}{2 R T}\right)
$$

where $k_{i}$ and $k_{i}^{-}$are the rate constants for the forward and backward reaction, [X] the activity of $\mathrm{X}$ species.

Assuming step 3 as the RDS, at equilibrium, there is no net oxygen flux across the surface/electrode and the $2 \mathrm{~PB}$ overpotential is zero. The exchange oxygen ion flux density of step $3, j_{3}^{0}$, is

$$
j_{3}^{0}=k_{3}\left[\mathrm{O}_{\mathrm{ads}}^{-}\right]\left[\mathrm{V}_{\mathrm{i}}^{\times}\right]=k_{3}^{-}\left[\mathrm{O}_{\mathrm{i}}^{\prime \prime}\right]
$$

At this moment, a false proportional dependency between $j_{3}^{0}$ and $\left[\mathrm{O}_{\mathrm{i}}^{\prime \prime}\right]$ is about tobe drawn if focusing on $k_{3}^{-}\left[\mathrm{O}_{\mathrm{i}}^{\prime \prime}\right]$ only, because the opposite can be arrived if instead considering the second term $k_{3}\left[\mathrm{O}_{\mathrm{ads}}^{-}\right]\left[\mathrm{V}_{\mathrm{i}}^{\times}\right]$. The cause of such discrepancy lies in the unique feature of this reaction: site conservation.

Interstitial site conservation in R-P phase gives

$$
\left[\mathrm{O}_{\mathrm{i}}^{\prime \prime}\right]+\left[\mathrm{V}_{\mathrm{i}}^{\times}\right]=\mathrm{C}
$$

where $\mathrm{C}$ is a constant.

Inserting Eq. 4-12 into Eq. 4-11 gives 


$$
K_{3}=\frac{k_{3}}{k_{3}^{-}}=\frac{1}{\left[\mathrm{O}_{\mathrm{ads}}^{-}\right]\left(\frac{\mathrm{C}}{\left[\mathrm{o}_{\mathrm{i}}^{\prime \prime}\right]}-1\right)}
$$

Where $K_{3}$ is the equilibrium constant of step 3. It is found that $K_{3}$ will increase with $\left[\mathrm{O}_{\mathrm{i}}^{\prime \prime}\right]$ provided $\left[\mathrm{O}_{\mathrm{ads}}^{-}\right]$is not directly dependent on $\left[\mathrm{O}_{\mathrm{i}}^{\prime \prime}\right]$, meaning $k_{3}$ may increase and/or $k_{3}^{-}$may decrease as $\left[\mathrm{O}_{\mathrm{i}}^{\prime \prime}\right]$ rises.

Combining Eq. 4-11and 4-12 to eliminate $\left[\mathrm{O}_{\mathrm{i}}^{\prime \prime}\right]$ and $\left[\mathrm{V}_{\mathrm{i}}^{\times}\right]$, one obtains

$$
j_{3}^{0}=\frac{\mathrm{C}}{\frac{1}{k_{3}\left[\mathrm{O}_{\mathrm{ads}}^{-}\right]}+\frac{1}{k_{3}^{-}}}
$$

By appropriately setting the evolution of $k_{3}$ and $k_{3}^{-}$towards [ $\mathrm{O}_{\mathrm{i}}^{\prime \prime}$, a non-monotonic relationship between $\left[\mathrm{O}_{\mathrm{i}}^{\prime \prime}\right]$ and $j_{3}^{0}$ can be established. A possible scenario is qualitatively illustrated in Fig. 4.8. In this diagram, $k_{3}$ increases and $k_{3}^{-}$decreases with $\left[\mathrm{O}_{\mathrm{i}}^{\prime \prime}\right]$ according to the dependency of $K_{3}$ on $\left[\mathrm{O}_{\mathrm{i}}^{\prime \prime}\right]$ in Eq. 4-13. Within [ $\left.\mathrm{O}_{\mathrm{i}}^{\prime \prime}\right]$ poor region, $k_{3}$ is set to change more drastically than $k_{3}^{-}$; in the $\left[\mathrm{V}_{\mathrm{i}}{ }^{\times}\right]$poor region, the opposite is valid. Due to the different gradients for $k_{3}$ and $k_{3}^{-}$vs. $\left[\mathrm{O}_{\mathrm{i}}^{\prime \prime}\right], j_{3}^{0}$ reaches its maximum at a certain $\left[\mathrm{O}_{\mathrm{i}}^{\prime \prime}\right]$ value according to Eq. 4-14. Over that point, going forward to increase $\left[\mathrm{O}_{\mathrm{i}}^{\prime \prime}\right]$ or backward to increase $\left[\mathrm{V}_{\mathrm{i}}^{\times}\right]$ will lead to decrease in $j_{3}^{0}$.

It seems that the constant $\mathrm{C}$ in Eq. 4-12 should be determined under the charge neutrality corresponding to Ni oxidation status $\left(\mathrm{C}=0.25\right.$ at $\left.\mathrm{Ni}^{3+}\right)$. However, as the interstitial vacancies in $\mathrm{La}_{2} \mathrm{O}_{2}$ layer are equivalent in the incorporation reaction and each site has the same chance to accommodate an adsorbed oxygen ion, it makes more sense to take $\mathrm{C}$ as the maximum interstitial sites in the rock salt layer, that is, 2 per unit cell. The reported $\delta$ values for LSNO in cathode condition are about 0.15 and turn fewer after Sr doping,[38, 40, $78]$ which belongs to the $\left[\mathrm{O}_{\mathrm{i}}^{\prime \prime}\right]$ poor region. In this case, increasing $\left[\mathrm{O}_{\mathrm{i}}^{\prime \prime}\right]$ results in enlarged $j_{3}^{0}$. Likewise, a similar diagram can be built for perovskites, except $\mathrm{C}$ being 3 per unit cell. The reported $\left[\mathrm{V}_{\mathrm{O}}\right]$ for the perovskites seldom exceeds 0.5 , which probably belongs to $\left[\mathrm{V}_{\mathrm{O}}\right]$ poor region. As a result, increasing $\left[\mathrm{V}_{\mathrm{O}}\right]$ will increase the exchange rate of incorporation 
reaction in perovskites. By this fashion, the contradiction mentioned before could be resolved.

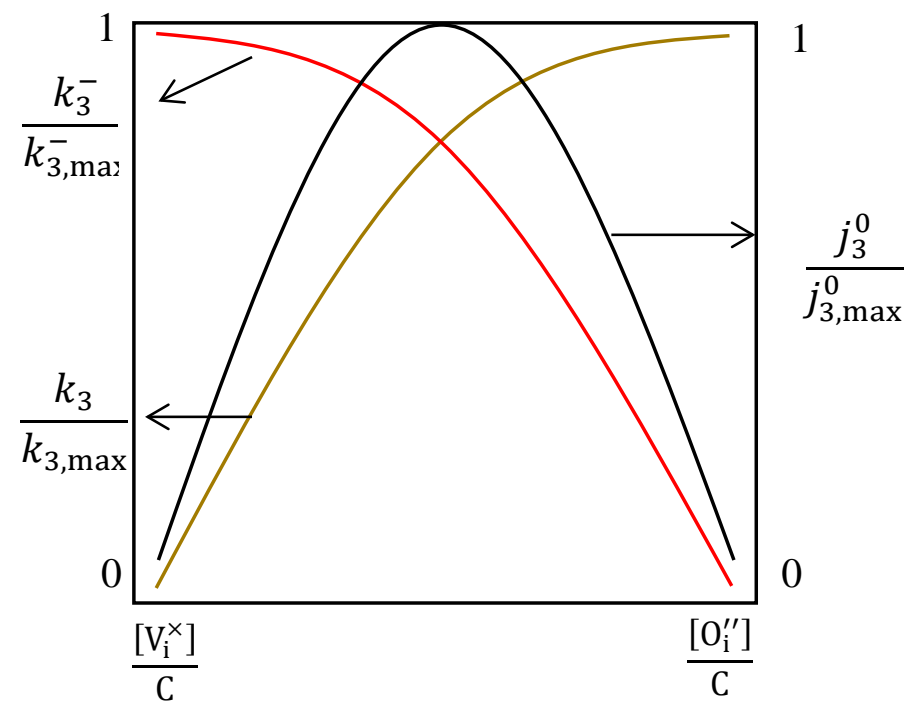

Fig. 4.8 Evolution of $k_{3}$ and $k_{3}^{-}$, and the resultant $j_{3}^{0}$ with $\left[\mathrm{O}_{\mathrm{i}}^{\prime \prime}\right]$.

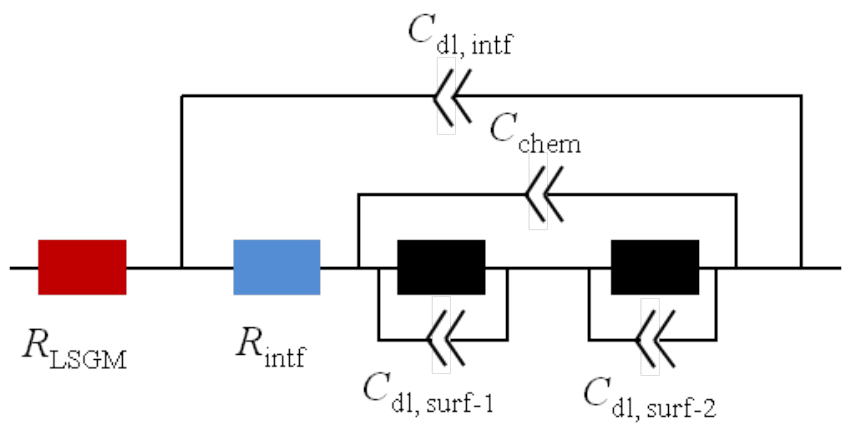

Fig. 4.9 Equivalent circuit for LSNO with two subsequent surface processes.

Some analysis can be conducted to the check the possibility of the scenario in Fig. 4.9. The feasibility of building such parabolic profile for $j_{3}^{0}$ relies on the variability of $K_{3}$, then $k_{3}$ and $k_{3}^{-}$. For normal chemical reactions where the initial concentrations of reactants/products are independent of each other, the equilibrium constants can really be constant, and certainly the reaction rate constants are related to Ea, temperature $\left(k_{i} \propto\right.$ $\left.\exp \left(\frac{-E_{a}}{R T}\right)\right)$ only, other than to the concentrations of reactants/products. But because of the site conservation in defect chemistry which puts an extra restriction on step 3, the 
development of equilibrium is hence partially influenced by Eq.4-11 which, when combined with Eq.4-10, leads to Eq.4-12, indicating that $K_{3}$ could alter with $\left[\mathrm{O}_{\mathrm{i}}^{\prime \prime}\right]$. This observation has been favored by the changeable $E$ a for $\left[\mathrm{O}_{\mathrm{i}}^{\prime \prime}\right]$ formation depending onthe oxygen stoichiometry of the R-P phase materials.[58]

As reported, the uptake of $\mathrm{O}_{\mathrm{i}}^{\prime \prime}$ is an exothermic process, $E_{\mathrm{a} \text {,forward }}<$ $E_{\text {a,backward, }}[56,58]$ which consequently lead to a judgment that $E_{\mathrm{a} \text {,forward }}$ decreases, and $E_{\mathrm{a} \text {,backward }}$ increases with $\left[\mathrm{O}_{\mathrm{i}}^{\prime \prime}\right]$ if the trends of $k_{3}$ and $k_{3}^{-}$vs. $\left[\mathrm{O}_{\mathrm{i}}^{\prime \prime}\right]$ in Fig. 4.9 is valid. It in turn gives rise to the prediction that the formation enthalpy for $\left[\mathrm{O}_{i}^{\prime \prime}\right]$ decreases (more negative) with increasing $\left[\mathrm{O}_{\mathrm{i}}^{\prime \prime}\right]$, and vice versa. The supportive evidences about this prediction can actually be found. Firstly, an increased enthalpy with Sr doping is implied by the phenomenon that $\left[\mathrm{O}_{\mathrm{i}}^{\prime \prime}\right]$ in LSNO decreases as $\mathrm{Sr},[38,40]$ which corresponds to a weakened driving force for the formation of $\mathrm{O}_{\mathrm{i}}^{\prime \prime}$ as Sr doping.Secondly, the partial molar enthalpy of $\mathrm{O}_{\mathrm{i}}^{\prime \prime}$ formation in LSNO have been calculated by Nakamura et al,[58]and such value is found to enlarge with increasing $\mathrm{Sr}$ (less $\mathrm{O}_{\mathrm{i}}^{\prime \prime}$ ) in the whole oxygen hyperstoichiometry region, enabling the possibility that at a fixed $P_{\mathrm{O} 2}$ the formation enthalpy increases with Sr doping. Nevertheless, it is particularly notable that the enthalpy tendency towards $\left[\mathrm{O}_{\mathrm{i}}^{\prime \prime}\right]$ triggered by Sr doping in LSNO might be not applicable to the change induced by $\left.P_{\mathrm{O} 2 \text { variation, because }\left[\mathrm{O}_{\mathrm{ads}}^{-}\right.}\right]$in Eq. 13 is assumed to be constant upon $\left[\mathrm{O}_{\mathrm{i}}^{\prime \prime}\right]$ change, which in fact is explicitly dependent on $P_{\mathrm{O} 2}$.

In above deviation, the activity of electron is left out assuming it is sufficient in all LSNO samples. $\left[\mathrm{O}_{\mathrm{ads}}^{-}\right]$is taken as a fixed value which probably varies more or less at different $\mathrm{Sr}$ contents. In addition, the deviation is mathematically qualitative. However, in spite of all these assumptions, such model is a meaningful try to exploit the role of $\mathrm{O}_{\mathrm{i}}^{\prime \prime}$ in surface exchange kinetics for the R-P phase structure materials.

\subsection{Summary}

In this chapter, ORR kinetics for surface for the R-P phase structure is investigated with LSNO dense cathodes by EIS in this study. With the well-defined geometry, accurate 
surface reaction resistances are obtained. The results clearly prove that Sr slows down the ORR kinetics. LNO yields a surface exchange coefficient of $8.59 \times 10^{-7} \mathrm{~cm} / \mathrm{s}$ at $700^{\circ} \mathrm{C}$. $\mathrm{Sr}$ doping decreases such value to $2.65 \times 10^{-7} \mathrm{~cm} / \mathrm{s}$ for Sr20, $1.68 \times 10^{-7} \mathrm{~cm} / \mathrm{s}$ for Sr40. RDS are identified based on the reaction order. Even though those $n$ values from ORR on dense cathodes show consistency with the judgment on RDS in our prior study, it is clearly addressed here that the practice of using reaction order to determine RDS should be conducted with caution due to the limitation associated with the basic assumptions in the deviation of reaction orders, especially on materials with readily changeable oxygen stoichiometry. Dissociative adsorption and ion incorporation are presented as the limiting factors for ORR on LSNO in combined consideration of the EIS results and independent observations reported in literature. In the incorporation process, $\mathrm{O}_{\mathrm{i}}^{\prime \prime}$ in rock salt layers is suggested to mediate the exchange rate of such elementary step, therefore show substantial influence on the final performance. A model is proposed, for the first time, to illustrate the possible wayO $\mathrm{O}_{\mathrm{i}}^{\prime \prime}$ works to realize its positive effect on the incorporation rate of such unique R-P phase structure. 


\section{Chapter 5: Improvement of surface kinetics by Mn\&Sr doping}

From previous work we already knew, for R-P phase materials, the interstitial oxygen are more active than vacancy in ABO3 layer in terms of incorporation, and $\mathrm{Ni}$ is the main active site for oxygen adsorption process. Combining these two key results we choose Mn substitution Ni into the lattice of R-P phase to enhance the surface kinetics. Mn has strong ability of adsorbing oxygen which is already verified from the good $k$ in LSM. On the other hand, Mn presents high state in R-P phase, which will be expected to produce the big amount of the interstitial oxygen.

$\mathrm{Mn}$ is found to substantially promote the surface kinetics, showing highest $k$ of $1.57 \times 10^{-6} \mathrm{~cm} / \mathrm{s}$ at $700^{\circ} \mathrm{C}$ on $\mathrm{La}_{1.8} \mathrm{Sr}_{0.2} \mathrm{Ni}_{0.9} \mathrm{Mn}_{0.1} \mathrm{O}_{4+\delta}$. Such value is $\sim 80 \%$ larger than that of the undoped sample, and is one of the highest $k$ among the currently available R-P phase intermediate temperature cathode.

\subsection{XRD and electrical conductivity of Mn\&Sr doped LNO}
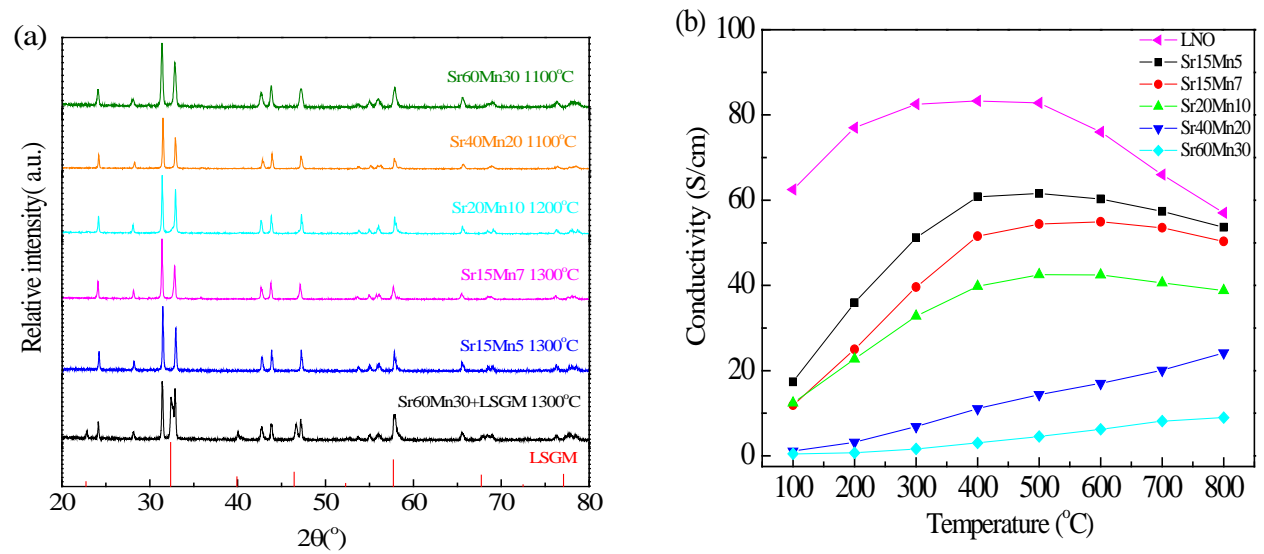

Fig. 5.1 a) XRD of LSNM samples synthesized at different temperatures and mixture of Sr60Mn30 and LSGM calcined at $1300^{\circ} \mathrm{C}$, b) electrical conductivities of LSNM in air from $100-800^{\circ} \mathrm{C}$.

Fig. 5.1a shows the phase purity of synthesized powders. In the Mn-based R-P phase studies, Munnings et al.[81] found that the single phase range for $\mathrm{La}_{2-\mathrm{x}} \mathrm{Sr}_{\mathrm{x}} \mathrm{MnO}_{4+\delta}$ is 
$0.6 \leq \mathrm{x} \leq 2$.0. Later on, Sun et al.[82] reported that such range is $1.4 \leq \mathrm{x} \leq 1.6$ when preparing in air. Although the exact Sr limit in the solid solution varies in above studies, both indicate that single phase is more favorable in the Sr-rich composition. It is indeed confirmed in the present work that $\mathrm{La}_{2} \mathrm{O}_{3}$ secondary phase appears in the composition $\mathrm{La}_{2} \mathrm{Ni}_{0.9} \mathrm{Mn}_{0.1} \mathrm{O}_{4+\delta}$. Therefore $\mathrm{Sr}$ was doped into LNO simultaneously with Mn to ensure the phase purity. The synthesis temperature for different doping levels varies and is marked in Fig. 5.1a. The final XRD patterns for all samples correspond to pure phase R-P structure (PDF 11-0557). As the dense symmetrical samples were prepared with LSGM electrolyte at high temperature, the chemical compatibility between LSNM and LSGM is examined through Sr60Mn30 and LSGM mixture sintered at $1300^{\circ} \mathrm{C}$ for $4 \mathrm{~h}$. As can been seen in Fig. 5.1a, no observable reaction is found.

Fig. 5.1b exhibits the electrical conductivity of LSNM. Mn doping decreases the conductivity gradually. Poor conductivity has been reported for $(\mathrm{LaSr})_{2} \mathrm{MnO}_{4+\delta}$ with the maximum less than $10 \mathrm{~S} / \mathrm{cm}$ when measured under $900^{\circ} \mathrm{C}$. It has been published that the electrical conductivity for pure LNO is thermally activated at low temperature as semiconductor, but turns oppositely to thermally deactivated like metal when temperature is higher than $\sim 600 \mathrm{~K}$.[83] LSNM with $\mathrm{Mn} \leq 10$ resemble the pure LNO behavior, but follow the semi-conducting trend of $(\mathrm{LaSr})_{2} \mathrm{MnO}_{4+\delta}$ at higher Mn levels. The ohmic resistance estimated from the electrical conductivities of Sr15Mn5, Sr15Mn7 and Sr20Mn10 with a typical electrode structure (porous electrode in thickness of $50 \mu \mathrm{m}, 1 / 10$ of the conductivity of dense bulk) is less than $0.0025 \Omega \mathrm{cm}^{2}$ in $600-800^{\circ} \mathrm{C}$, which in most cases is negligible compared to the cathode polarization resistances in the IT region.

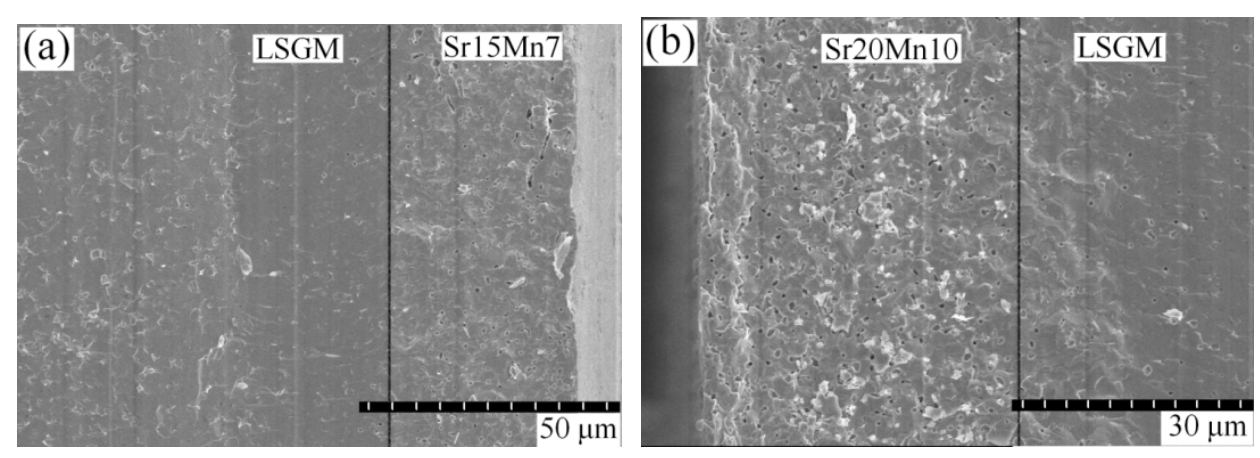




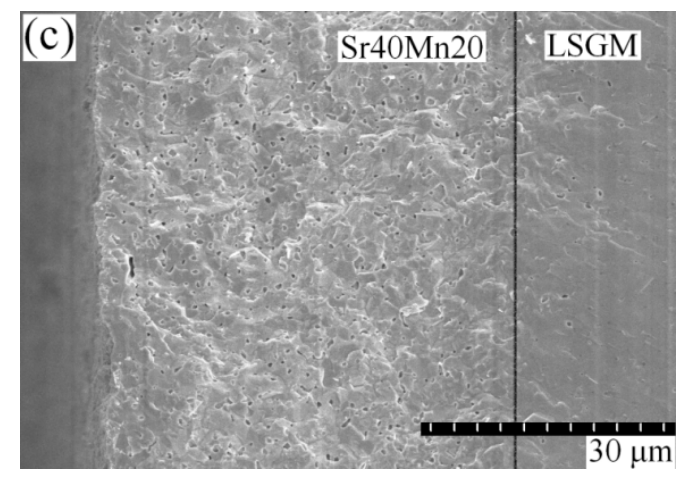

Fig.5. 2 Cross-section of (a) Sr15Mn7, (b) Sr20Mn10 and (c) Sr40Mn20-LSGM bilayers.

Fig. 5.2 shows the microstructure of Sr15Mn5/LSGM sample. Dense structure except for few of closed pin holes was obtained after $1300^{\circ} \mathrm{C}$ sintering. Good adhesion between Sr15Mn5 and LSGM is confirmed. No chemical reaction can be observed in the interface area, which is consistent with the XRD results. The small thickness of LSNM renders that the resistance from bulk diffusion in EIS characterization is marginal compared to the surface exchange process, given the characteristic length for LNO is 500 1000 $\mu \mathrm{m} .[35]$

\subsection{Surface improvement by Mn doping}

Fig. 5.3 shows the EIS arcs measured from LSNM symmetrical cells. To accurately assess the surface kinetics of cathode materials, dense thin layer has been widely adopted in literature in order to avoid bulk diffusion influence and complex microstructure in the standard porous electrode. An equivalent circuit for the dense electrode under surface exchange dominant situation has been derived elsewhere and is presented in Fig. 3. The combination of the $C_{\text {chem }}$ originated from oxygen stoichiometry change upon potential perturbation and the $R_{\text {surf }}$ is responsible for the main arc. Sr15Mn5 was fitted by this EC satisfactorily. The rest samples share the similar profile due to the same surface-dominant situation and were fitted into this EC also to yield $R_{\text {surf. }}$ 


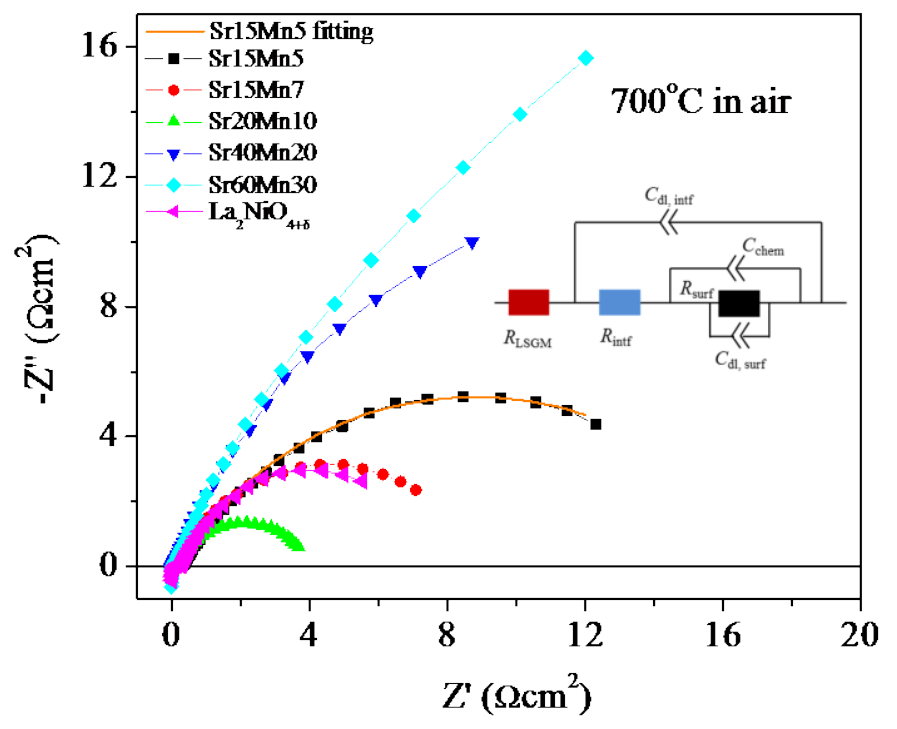

Fig.5.3 EIS of LSNM symmetrical cells at $700^{\circ} \mathrm{C}$ in air

The equivalent surface exchange coefficient can be calculated from $R_{\text {surf }}$ through Eq. $5-1,[71,72]$

$$
k=\frac{R T}{4 F^{2} R_{\text {surf }} c_{\mathrm{o}}}
$$

where $F$ is the Faraday's constant, $c_{0}$ the oxygen concentration in LSNM, $R$ and $T$ keep the usual physical meanings.

Fig. 5.4 displays the $k$ values for LSNM. The exchange rate ranks as Sr20Mn10 $>$ LNO $>$ Sr15Mn7>Sr15Mn5 $>$ Sr40Mn20 $>$ Sr60Mn30. $k$ for Sr20Mn10 is about twice bigger than that of the pristine LNO. The highest value is achieved by this modestly doped sample; increasing or decreasing Mn content further will lower the surface kinetics. To assess the real effect of $\mathrm{Mn}$ on this trend, both $\mathrm{Sr}$ and $\mathrm{Mn}$ need to be taken into account in such evolution of $k$. As stated before, although $\mathrm{Mn}$ is the designed substitute for $\mathrm{Ni}, \mathrm{Sr}$ has to be used to obtain single phase structure. It has been demonstrated in previous studies that $\mathrm{Sr}$ doping impairs the surface kinetics of LNO by increasing the oxidation state of $\mathrm{Ni}$ 
and reducing interstitial oxygen population[68, 84].Thus, the improvement from $\mathrm{Mn}$ doping could be partially offset by Sr.

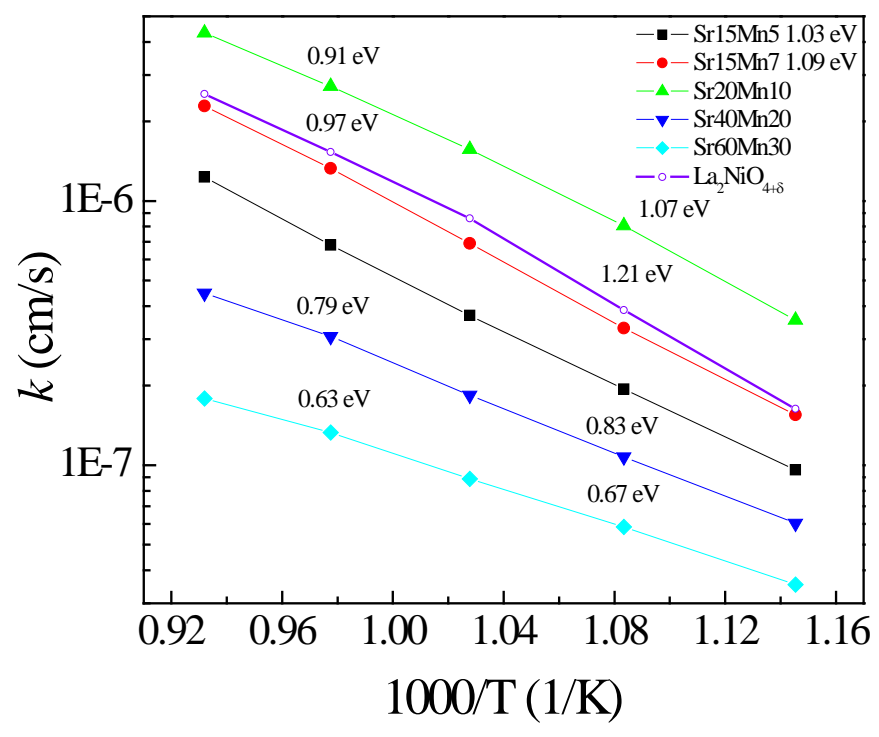

Fig. 5.4 Equivalent $k$ for LSNM calculated from $R_{\text {surf }}$

Due to this very concern, Sr15Mn5 sample was prepared. Comparing Sr15Mn5 and Sr15Mn7, with fixed Sr level, $k$ is increased from $3.7 \times 10^{-7}$ to $6.9 \times 10^{-7} \mathrm{~cm} / \mathrm{s}$ at $700^{\circ} \mathrm{C}$ by the extra 2.5\% Mn content, which ambiguously proves the advantageous effect of Mn. On the other hand, Daroukh et al.[85] found that full $\mathrm{Mn} \mathrm{B}$ site $\mathrm{La}_{0.5} \mathrm{Sr}_{1.5} \mathrm{MnO}_{4}$ tends to keep the exact stoichiometry in a wide range of $P_{\mathrm{O} 2}$ with strong reluctance to either accommodate interstitial oxygen or lose lattice oxygen to form vacancy. As the interstitial oxygen is crucial to the ion incorporation, high Mn content will probably lead to decreased exchange rate when limited by the incorporation process. As a result, the optimum Mn content should be the one balancing the rate limits from surface adsorption and ionic incorporation. The apparent activation energy is derived based on this Arrhenius plot. It is reduced gradually in those $\mathrm{Mn} \geq 10$ samples compared to LNO, indicating an energetically more favorable surface process with Mn presence.

Table 5-1 summarizes some of the most commonly used R-P phase cathodes. Sr20Mn10 from this work displays one of the best $k$ values, $1.57 \times 10^{-6} \mathrm{~cm} / \mathrm{s}$ at $700^{\circ} \mathrm{C}$, which 
is much better than its Co or Fe doped counterpart, demonstrating the substantial advantage of $\mathrm{Mn}$ over other dopants. At last, since the $\mathrm{Sr} / \mathrm{Mn}=2$ ratio was empirically chosen, higher surface performance can be reasonably expected through systematical study on the $\mathrm{Sr}$ content in the future.

Table 5-1 Comparison of $k$ for common R-P phase cathodes at $700^{\circ} \mathrm{C}$

\begin{tabular}{llll}
\hline & $k(\mathrm{~cm} / \mathrm{s})$ & $E \mathrm{a}(\mathrm{eV})$ & Ref. \\
\hline $\mathrm{Sr} 20 \mathrm{Mn10}$ & $1.57 \times 10^{-6}$ & $0.91 \sim 1.07$ & This work \\
$\mathrm{La}_{2} \mathrm{Ni}_{0.9} \mathrm{Co}_{0.1} \mathrm{O}_{4+\delta}$ & $1.41 \times 10^{-6}$ & 0.6 & {$[67]$} \\
$\mathrm{Pr}_{2} \mathrm{NiO}_{4+\delta}$ & $1.0 \times 10^{-6}$ & 0.77 & {$[45]$} \\
$\mathrm{LNO}$ & $8.6 \times 10^{-7}$ & $0.97 \sim 1.21$ & This work \\
$\mathrm{La}_{2} \mathrm{Ni}_{0.9} \mathrm{Fe}_{0.1} \mathrm{O}_{4+\delta}$ & $4.0 \times 10^{-7}$ & 1.39 & {$[86]$} \\
$\mathrm{La}_{1.8} \mathrm{Sr}_{0.2} \mathrm{NiO}_{4+\delta}$ & $2.7 \times 10^{-7}$ & $1.06 \sim 1.37$ & Our work \\
$\mathrm{Nd}_{1.8} \mathrm{Ca}_{0.2} \mathrm{NiO}_{4+\delta}$ & $1.5 \times 10^{-7}$ & 1.35 & [45] \\
\hline
\end{tabular}

\subsection{Summary}

Mn doped $(\mathrm{LaSr})_{2} \mathrm{Ni}_{1-\mathrm{x}} \mathrm{Mn}_{\mathrm{x}} \mathrm{O}(0.05 \leq \mathrm{Mn} \leq 0.3)$ are investigated as IT cathode candidates for enhanced surface exchange kinetics. Pure phase was obtained at $\mathrm{Mn \& Sr}$ doped into LNO simultaneously. The surface exchange resistance was evaluated by EIS on the dense thin layer structure. The best performance was obtained from Sr20Mn10. $k$ for such composition is $1.57 \times 10^{-6} \mathrm{~cm} / \mathrm{s}$ at $700^{\circ} \mathrm{C}$ in air, approximately twice bigger than that for the pristine LNO. Of the often used R-P phase cathode materials, Sr20Mn10displays one of the greatest $k$ values, proving Mn doping is successful and more effective than $\mathrm{Co}$ and $\mathrm{Fe}$ in terms of surface kinetics. With optimization of $\mathrm{Sr}$ content, further improvement in $k$ can be reasonably anticipated. 


\section{Chapter6: Conclusion}

In this thesis, investigation of Sr doped MIEC cathode in Ruddles-Popper phase $\mathrm{La}_{2} \mathrm{NiO}_{4+\mathrm{x}}$ oxides has been conducted. ORR kinetics of LNO is discussed though the effect of Sr doping on electrode performance. The best performance was obtained with the undoped material, and Sr doping increased the polarization resistance. The surface exchange and bulk/surface diffusion co-controlling situation is observed. Significant bulk active lengths are confirmed through the chemical capacitance, 3.9 and $3.4 \mu \mathrm{m}$ for LNO and Sr10 at $600{ }^{\circ} \mathrm{C}$, respectively, indicating the importance of bulk diffusion contribution in determining the electrode performance. On the other hand, for the surface exchange reaction, oxygen dissociative adsorption is suggested to be the primary elementary step meditating the exchange kinetics. The impaired adsorption ability after $\mathrm{Sr}$ doping is associated to the increased oxidation state of $\mathrm{Ni}$.

Surface exchange kinetics was further discussed in a well-defined dense electrode configuration. Dense cathode cells were made by using a novel spray-modified pressing method. With the simple geometry, accurate surface reaction resistances are obtained in dense cathode. Dissociative adsorption and ion incorporation are presented as the limiting factors for surface reaction on LSNO in combined consideration of the EIS results and independent observations reported in literature. In the incorporation process, $\mathrm{O}_{\mathrm{i}}^{\prime \prime}$ in rock salt layers is suggested to mediate the exchange rate of such elementary step, therefore show substantial influence on the final performance. A model is proposed to illustrate the possible way $\mathrm{O}_{\mathrm{i}}^{\prime \prime}$ works to realize its positive effect on the incorporation rate of such unique $\mathrm{R}-\mathrm{P}$ phase structure. It is found that the amount of $\mathrm{O}_{\mathrm{i}}^{\prime \prime}$ affects its formation energy in the site conserved lattice structure, which in turn changes the activation energy of forward/backward reaction rate.

$\mathrm{Mn}$ is chosen as B site dopant in $(\mathrm{LaSr})_{2} \mathrm{Ni}_{1-\mathrm{x}} \mathrm{Mn}_{\mathrm{x}} \mathrm{O}(0.05 \leq \mathrm{Mn} \leq 0.3)$ in order to enhance the surface exchange kinetics. Pure phase was obtained at Mn\&Sr doped into LNO simultaneously. The surface exchange resistance was evaluated by EIS on the dense thin layer structure. The best performance was obtained from Sr20Mn10. $k$ for such 
composition is $1.57 \times 10^{-6} \mathrm{~cm} / \mathrm{s}$ at $700^{\circ} \mathrm{C}$ in air, approximately twice bigger than that for the pristine LNO. Of the often used R-P phase cathode materials, Sr20Mn10 displays one of the greatest $k$ values, proving Mn doping is successful and more effective than Co and Fe in terms of surface kinetics. With optimization of Sr content, further improvement in $k$ can be reasonably anticipated. 


\section{References}

1. Stambouli, A.B. and E. Traversa, Solid oxide fuel cells (SOFCs): a review of an environmentally clean and efficient source of energy. Renewable and Sustainable Energy Reviews, 2002. 6(5): p. 433-455.

2. Stambouli, A.B. and E. Traversa, Fuel cells, an alternative to standard sources of energy. Renewable and Sustainable Energy Reviews, 2002. 6(3): p. 295-304.

3. Steele, B.C. and A. Heinzel, Materials for fuel-cell technologies. Nature, 2001. 414(6861): p. 345-352.

4. Shen, Y., et al., Preparation and electrical properties of Ca-doped La $2 \mathrm{NiO} 4+\delta$ cathode materials for IT-SOFC. Physical Chemistry Chemical Physics, 2010. 12(45): p. 15124-15131.

5. Adler, S.B., J. Lane, and B. Steele, Electrode Kinetics of Porous Mixed Conducting Oxygen Electrodes. Journal of The Electrochemical Society, 1996. 143(11): p. 3554-3564.

6. Amow, G. and S. Skinner, Recent developments in Ruddlesden-Popper nickelate systems for solid oxide fuel cell cathodes. Journal of Solid State Electrochemistry, 2006. 10(8): p. 538-546.

7. Minh, N. and T. Takahashi, Science and technology of ceramic fuel cells, 1995. ISBN 0. 444: p. 89568.

8. Singhal, S.C. and K. Kendall, High-temperature solid oxide fuel cells: fundamentals, design and applications: fundamentals, design and applications2003: Elsevier.

9. $\quad$ Gellings, P.J. and H. Bouwmeester, Handbook of solid state electrochemistry1997: CRC press.

10. Tsai, T. and S.A. Barnett, Effect of LSM-YSZ cathode on thin-electrolyte solid oxide fuel cell performance. Solid State Ionics, 1997. 93(3): p. 207-217.

11. De Souza, R., J. Kilner, and J. Walker, A SIMS study of oxygen tracer diffusion and surface exchange in La 0.8 Sr 0.2 MnO 3+ $\delta$. Materials Letters, 2000. 43(1): p. 4352. 
12. Kawada, T., et al., Determination of oxygen vacancy concentration in a thin film of LaO. 6Sr0. 4CoO3- $\delta$ by an electrochemical method. Journal of The Electrochemical Society, 2002. 149(7): p. E252-E259.

13. Zipprich, W., et al., Improved preparation of La 1-x Me $x \mathrm{CoO} 3-\delta(\mathrm{Me}=\mathrm{Sr}, \mathrm{Ca})$ and analysis of oxide ion conductivity with ion conducting microcontacts. Solid State Ionics, 1997. 101: p. 1015-1023.

14. Senarıs-Rodriguez, M. and J. Goodenough, Magnetic and Transport Properties of the System La1-xSrxCoO3- $\delta(0<x \leqslant 0.50)$. Journal of Solid State Chemistry, 1995. 118(2): p. 323-336.

15. Taskin, A., A. Lavrov, and Y. Ando, Transport and magnetic properties of $G d B a$ Co 2 O 5+ x single crystals: A cobalt oxide with square-lattice Co O 2 planes over a wide range of electron and hole doping. Physical Review B, 2005. 71(13): p. 134414.

16. Taskin, A., A. Lavrov, and Y. Ando, Fast oxygen diffusion in A-site ordered perovskites. Progress in Solid State Chemistry, 2007. 35(2): p. 481-490.

17. Stern, D.L. and R.K. Grasselli, Reaction network and kinetics of propane oxydehydrogenation over nickel cobalt molybdate. Journal of catalysis, 1997. 167(2): p. 560-569.

18. Huang, S., et al., Ba0. 9Co0. 7Fe0. 2Mo0. 103 - $\delta$ : A Promising Single - Phase Cathode for Low Temperature Solid Oxide Fuel Cells. Advanced Energy Materials, 2011. 1(6): p. 1094-1096.

19. Tarancón, A., et al., Stability, chemical compatibility and electrochemical performance of GdBaCo $2 \mathrm{O} 5+x$ layered perovskite as a cathode for intermediate temperature solid oxide fuel cells. Solid State Ionics, 2008. 179(40): p. 2372-2378.

20. Nagai, T., W. Ito, and T. Sakon, Relationship between cation substitution and stability of perovskite structure in $\mathrm{SrCoO} 3-\delta$-based mixed conductors. Solid State Ionics, 2007. 177(39): p. 3433-3444.

21. Deng, Z., et al., B Cation Ordered Double Perovskite Ba2CoMo0. 5Nb0. 5O6- $\delta$ As a Potential SOFC Cathode. Chemistry of Materials, 2009. 21(21): p. 5154-5162. 
22. Zhao, K., et al., Electrochemical evaluation of La2NiO4+ $\delta$-based composite electrodes screen-printed on Ce0. 8Sm0. 2O1. 9 electrolyte. Journal of Solid State Electrochemistry, 2012. 16(8): p. 2797-2804.

23. Mauvy, F., et al., Electrode properties of Ln2NiO4 $+\delta(L n=L a, N d, P r): A C$ Impedance and DC Polarization Studies. Journal of the Electrochemical Society, 2006. 153(8): p. A1547-A1553.

24. Aguadero, A., et al., In situ high temperature neutron powder diffraction study of oxygen-rich La2NiO4+ $\delta$ in air: correlation with the electrical behaviour. Journal of Materials Chemistry, 2006. 16(33): p. 3402-3408.

25. Jeon, S.-Y., et al., Oxygen ionic conductivity of $\mathrm{La}<\mathrm{sub}>2</ \mathrm{sub}>\mathrm{NiO}<\mathrm{sub}>4+$ $\delta</$ sub $>$ via interstitial oxygen defect. Journal of Physics and Chemistry of Solids, 2012. 73(5): p. 656-660.

26. Skinner, S. and J. Kilner, Oxygen diffusion and surface exchange in La $<$ sub $>2-$ $x</ s u b>\mathrm{Sr}<\mathrm{sub}>x</ s u b>\mathrm{NiO}<\mathrm{sub}>4+\delta</ s u b>$. Solid State Ionics, 2000. 135(1): p. 709-712.

27. Tarancón, A., et al., Advances in layered oxide cathodes for intermediate temperature solid oxide fuel cells. Journal of Materials Chemistry, 2010. 20(19): p. 3799-3813.

28. Choi, S., et al., High Performance SOFC Cathode Prepared by Infiltration of La n+ $1 N i n$ O3 $n+1$ ( $n=1,2$, and 3) in Porous YSZ. Journal of the Electrochemical Society, 2011. 158(8): p. B995-B999.

29. Ferkhi, M., et al., $L a<s u b>1.98</$ sub $>N i 0<s u b>4 \pm \delta</$ sub $>$, a new cathode material for solid oxide fuel cell: Impedance spectroscopy study and compatibility with gadolinia-doped ceria and yttria-stabilized zirconia electrolytes.

Electrochimica Acta, 2012. 75: p. 80-87.

30. Jorgensen, J., et al., Structure of the interstitial oxygen defect in $\mathrm{La} 2 \mathrm{NiO} 4+\delta$. Physical Review B, 1989. 40(4): p. 2187.

31. Takeda, Y., et al., Crystal chemistry and physical properties of La2-xSrxNiO4 (0 $\leqslant x \leqslant 1.6$ ). Materials research bulletin, 1990. 25(3): p. 293-306. 
32. Tamura, H., A. Hayashi, and Y. Ueda, Phase diagram of La2NiO4+ $\delta(0 \leqslant \delta \leqslant$ 0.18): I. Phase at room temperature and phases transition above $\delta=0.15$. Physica C: Superconductivity, 1993. 216(1 - 2): p. 83-88.

33. Sayers, R., et al., Low temperature diffusion and oxygen stoichiometry in lanthanum nickelate. Solid State Ionics, 2010. 181(8-10): p. 386-391.

34. Li, Y., K. Gerdes, and X. Liu, Oxygen Transport Kinetics in Infiltrated SOFCs Cathode by Electrical Conductivity Relaxation Technique. Journal of the Electrochemical Society, 2013. 160(6): p. F554-F559.

35. Kim, G., et al., Measurement of oxygen transport kinetics in epitaxial La $2 \mathrm{NiO} 4+$ $\delta$ thin films by electrical conductivity relaxation. Solid State Ionics, 2006. 177(17): p. 1461-1467.

36. Ganeshananthan, R. and A.V. Virkar, Measurement of Transport Properties by Conductivity Relaxation on Dense La0. 6Sr0. 4CoO3- $\delta$ With and Without Porous Surface Layers. Journal of the Electrochemical Society, 2006. 153(12): p. A2181A2187.

37. Nakamura, T., et al., Electronic state of oxygen nonstoichiometric La2$x$ SrxNiO4 $+\delta$ at high temperatures. Physical Chemistry Chemical Physics, 2009. 11(17): p. 3055-3062.

38. Vashook, V., et al., Oxygen nonstoichiometry and electrical conductivity of the solid solutions $\mathrm{La}<\mathrm{sub}>2-x</ s u b>\mathrm{Sr}<\mathrm{sub}>x</$ sub $>\mathrm{NiO}<\mathrm{sub}>y</$ sub $>(0 \leqslant$ $<i>x</ i>\leqslant 0.5$ ). Solid State Ionics, 1998. 110(3): p. 245-253.

39. Nakamura, T., et al., Thermally-induced and chemically-induced structural changes in layered perovskite-type oxides $\mathrm{Nd} 2-x \mathrm{Sr} x \mathrm{NiO} 4+\delta(x=0,0.2,0.4)$. Solid State Ionics, 2010. 181(8): p. 402-411.

40. Vashook, V., et al., Composition and conductivity of some nickelates. Solid State Ionics, 1999. 119(1): p. 23-30.

41. Adler, S., J. Lane, and B. Steele, Electrode Kinetics of Porous Mixed - Conducting Oxygen Electrodes. Journal of the Electrochemical Society, 1996. 143(11): p. 35543564. 
42. Adler, S., Limitations of charge-transfer models for mixed-conducting oxygen electrodes. Solid State Ionics, 2000. 135(1): p. 603-612.

43. Boukamp, B.A. and H.J.M. Bouwmeester, Interpretation of the Gerischer impedance in solid state ionics. Solid State Ionics, 2003. 157(1-4): p. 29-33.

44. Nielsen, J., T. Jacobsen, and M. Wandel, Impedance of porous IT-SOFC LSCF: CGO composite cathodes. Electrochimica Acta, 2011. 56(23): p. 7963-7974.

45. Boehm, E., et al., Oxygen diffusion and transport properties in non-stoichiometric Ln 2- x NiO 4+ $\delta$ oxides. Solid State Ionics, 2005. 176(37): p. 2717-2725.

46. Hjalmarsson, P., M. Sogaard, and M. Mogensen, Oxygen transport properties of dense and porous (La0. 8Sr0. 2) 0.99 Co0. 8Ni0. 2O3- $\delta$. Solid State Ionics, 2009. 180(23-25): p. 1290-1297.

47. González-Cuenca, M., et al., Impedance Studies on Chromite-Titanate Porous Electrodes under Reducing Conditions. Fuel Cells, 2001. 1(3-4): p. 256-264.

48. Boukamp, B.A., Electrochemical impedance spectroscopy in solid state ionics: recent advances. Solid State Ionics, 2004. 169(1): p. 65-73.

49. Leng, Y., S.H. Chan, and Q. Liu, Development of LSCF-GDC composite cathodes for low-temperature solid oxide fuel cells with thin film GDC electrolyte. International Journal of Hydrogen Energy, 2008. 33(14): p. 3808-3817.

50. Aguadero, A., et al., Hyperstoichiometric La1. 9SrO. 1NiO4+ $\delta$ mixed conductor as novel cathode for intermediate temperature solid oxide fuel cells. Journal of Fuel Cell Science and Technology, 2007. 4(3): p. 294-298.

51. Kim, J.D., et al., Characterization of LSM-YSZ composite electrode by ac impedance spectroscopy. Solid State Ionics, 2001. 143(3): p. 379-389.

52. Escudero, M., et al., A kinetic study of oxygen reduction reaction on $L a<s u b>$ $2</$ sub $>\mathrm{NiO}<\mathrm{sub}>4</$ sub $>$ cathodes by means of impedance spectroscopy. Journal of Electroanalytical Chemistry, 2007. 611(1): p. 107-116.

53. Li, W., M. Gong, and X. Liu, Characterization of Doped Yttrium Chromites as Electrodes for Solid Oxide Fuel Cell by Impedance Method. Journal of the Electrochemical Society, 2014. 161(4): p. F551-F560. 
54. Baumann, F.S., et al., Impedance spectroscopic study on well-defined $(\mathrm{La}, \mathrm{Sr})(\mathrm{Co}, \mathrm{Fe}) \mathrm{O3}-\delta$ model electrodes. Solid State Ionics, 2006. 177(11-12): p. 1071-1081.

55. Adler, S.B., Factors governing oxygen reduction in solid oxide fuel cell cathodes. Chemical Reviews-Columbus, 2004. 104(10): p. 4791-4844.

56. $\quad \mathrm{Li}, \mathrm{Z}$., et al., Transport properties and defect analysis of $\mathrm{La} 1.9 \mathrm{Sr} 0.1 \mathrm{NiO} 4+\delta$. Solid State Ionics, 2009. 180(26): p. 1433-1441.

57. Kim, G.T., et al., Impedance studies of dense polycrystalline thin films of La $2 \mathrm{NiO}$ $4+\delta$. Journal of Materials Chemistry, 2007. 17(13): p. 1316-1320.

58. Nakamura, T., et al., Oxygen nonstoichiometry and defect equilibrium in $\mathrm{La} 2-x \mathrm{Sr}$ $x \mathrm{NiO} 4+\delta$. Solid State Ionics, 2009. 180(4): p. 368-376.

59. Lu, Y., C. Kreller, and S.B. Adler, Measurement and Modeling of the Impedance Characteristics of Porous La1 $-x \mathrm{Sr} x \mathrm{CoO} 3-\delta$ Electrodes. Journal of the Electrochemical Society, 2009. 156(4): p. B513-B525.

60. Boukamp, B., et al., SOFC-anodes, proof for a finite-length type Gerischer impedance? Solid State Ionics, 2006. 177(26): p. 2539-2541.

61. Adler, S., Mechanism and kinetics of oxygen reduction on porous $L a<s u b>1-$ $x</$ sub $>$ Sr $<$ sub $>x</$ sub $>\mathrm{CoO}<$ sub $>3-\delta</$ sub $>$ electrodes. Solid State Ionics, 1998. 111(1): p. 125-134.

62. Li, Z., R. Haugsrud, and T. Norby, Oxygen bulk diffusion and surface exchange in Sr-substituted La $2 \mathrm{NiO} 4+\delta$. Solid State Ionics, 2011. 184(1): p. 42-46.

63. Heuveln, F.H. and H. Bouwmeester, Electrode Properties of Sr-Doped LaMnO3 on Yttria-Stabilized Zirconia II: Electrode kinetics. Journal of the Electrochemical Society, 1997. 144(1): p. 134-140.

64. Li, W., M. Gong, and X. Liu, H2 Oxidation on Doped Yttrium Chromites/Yttrium Stabilized Zirconia Anode of Solid Oxide Fuel Cell. Journal of Power Sources, 2013. 241(0): p. 494-501.

65. Burriel, M., et al., Anisotropic oxygen diffusion properties in epitaxial thin films of $\mathrm{La2NiO4}+\delta$. Journal of Materials Chemistry, 2008. 18(4): p. 416-422.

66. Voorhoeve, R., et al., Perovskite oxides: Materials science in catalysis. Science, 1977. 195(4281): p. 827-833. 
67. Kilner, J.A. and C.K.M. Shaw, Mass transport in La2Ni1-xCoxO4 $+\delta$ oxides with the K2NiF4 structure. Solid State Ionics, 2002. 154-155(0): p. 523-527.

68. Lee, D., et al., Strontium Influence on the Oxygen Electrocatalysis of La2-xSrxNiO4 $\pm \delta(0.0 \leqslant x S r \leqslant 1.0)$ Thin Films. Journal of Materials Chemistry A, 2014.

69. Jamnik, J. and J. Maier, Treatment of the Impedance of Mixed Conductors Equivalent Circuit Model and Explicit Approximate Solutions. Journal of the Electrochemical Society, 1999. 146(11): p. 4183-4188.

70. Guan, B., et al., Oxygen Reduction Reaction Kinetics in Sr-Doped La2NiO4+ $\delta$ Ruddlesden-Popper Phase as Cathode for Solid Oxide Fuel Cells. Journal of The Electrochemical Society, 2015. 162(7): p. F707-F712.

71. Maier, J., On the correlation of macroscopic and microscopic rate constants in solid state chemistry. Solid State Ionics, 1998. 112(3): p. 197-228.

72. Fleig, J. and J. Maier, The polarization of mixed conducting SOFC cathodes: Effects of surface reaction coefficient, ionic conductivity and geometry. Journal of the European Ceramic Society, 2004. 24(6): p. 1343-1347.

73. Jung, W. and H.L. Tuller, A New Model Describing Solid Oxide Fuel Cell Cathode Kinetics: Model Thin Film SrTi1 - xFexO3 - $\delta$ Mixed Conducting Oxides - a Case Study. Advanced Energy Materials, 2011. 1(6): p. 1184-1191.

74. Kilner, J.A., R.A. De Souza, and I.C. Fullarton, Surface exchange of oxygen in mixed conducting perovskite oxides. Solid State Ionics, 1996. 86-88, Part 2(0): p. 703-709.

75. Merkle, R., J. Maier, and H.J. Bouwmeester, A Linear Free Energy Relationship for Gas - Solid Interactions: Correlation between Surface Rate Constant and Diffusion Coefficient of Oxygen Tracer Exchange for Electron - Rich Perovskites. Angewandte Chemie International Edition, 2004. 43(38): p. 5069-5073.

76. De Souza, R., A universal empirical expression for the isotope surface exchange coefficients $\left(k^{*}\right)$ of acceptor-doped perovskite and fluorite oxides. Physical Chemistry Chemical Physics, 2006. 8(7): p. 890-897.

77. De Souza, R. and J. Kilner, Oxygen transport in La1-xSrxMn1-yCoyO3 $\pm \delta$ perovskites: Part II. Oxygen surface exchange. Solid State Ionics, 1999. 126(1-2): p. 153-161. 
78. Naumovich, E., et al., Oxygen nonstoichiometry in La2Ni (M) O4+ $\delta(<i>$ $M</ \mathrm{i}>=\mathrm{Cu}$, Co) under oxidizing conditions. Solid State Sciences, 2005. 7(11): p. 1353-1362.

79. Shao, Z., W. Zhou, and Z. Zhu, Advanced synthesis of materials for intermediatetemperature solid oxide fuel cells. Progress in Materials Science, 2012. 57(4): p. 804-874.

80. Guan, B., et al., A Performance Study of Solid Oxide Fuel Cells With BaZr0. 1Ce0. 7Y0. 203 - $\delta$ Electrolyte Developed by Spray - Modified Pressing Method. Fuel Cells, 2012. 12(1): p. 141-145.

81. Munnings, C.N., et al., Structure, stability and electrical properties of the La $(2-x)$ $\operatorname{Sr} x \mathrm{MnO} 4 \pm \delta$ solid solution series. Solid State Ionics, 2006. 177(19): p. 1849-1853.

82. Liping, S., et al., La substituted $\mathrm{Sr} 2 \mathrm{MnO} 4$ as a possible cathode material in SOFC. Journal of Power Sources, 2008. 179(1): p. 96-100.

83. Nakamura, T., et al., Electronic state of oxygen nonstoichiometric La 2-x $\mathrm{Sr} x \mathrm{NiO}$ $4+\delta$ at high temperatures. Physical Chemistry Chemical Physics, 2009. 11(17): p. 3055-3062.

84. Guan, B., et al., Oxygen Reduction Reaction Kinetics in Sr-Doped La2NiO4+ $\delta$ Ruddlesden-Popper Phase as Cathode for Solid Oxide Fuel Cells. Journal of the Electrochemical Society, 2015. 162(7): p. F707-F712.

85. Al Daroukh, M., et al., Oxides of the AMO3 and A2MO4-type: structural stability, electrical conductivity and thermal expansion. Solid State Ionics, 2003. 158(1-2): p. 141-150.

86. Skinner, S. and J. Kilner, A comparison of the transport properties of La2$x$ SrxNi1 $-y$ FeyO4 $+\delta$ where $0<x<0.2$ and $0<y<0.2$. Ionics, 1999. 5(3-4): p. 171174.

87. Li, Y., et al., Surface Exchange and Bulk Diffusivity of LSCF as SOFC Cathode: Electrical Conductivity Relaxation and Isotope Exchange Characterizations. Journal of the Electrochemical Society, 2013. 160(4): p. F343-F350.

88. Guan, B., et al., Oxygen Reduction Reaction Kinetics in Sr-Doped La2NiO4+ $\delta$ Ruddlesden-Popper Phase as Cathode for Solid Oxide Fuel Cells. Journal of The Electrochemical Society, 2015. 162(7): p. F1-F6. 


\section{Published papers}

Bo Guan, Wenyuan Li, Hui Zhang, Xingbo Liu. Oxygen Reduction Reaction Kinetics in Sr-Doped La2NiO4+ $\delta$ Ruddlesden-Popper Phase as Cathode for Solid Oxide Fuel Cells. Journal of The Electrochemical Society, 2015, DOI:10.1149/2.0541507jes.

Bo Guan, Wenyuan Li, Xinxin Zhang, Xingbo Liu. Surface Oxygen Exchange Properties of Sr Doped La2NiO4+ $\delta$ as SOFC Cathode: Thin-Film Electrical Conductivity Relaxation Investigation. ECS Transactions, 2015, DOI:10.1149/06801.0801ecst

Wenyuan Li, Bo Guan, Xinxin Zhang, Jianhua Yan, Yue Zhou, Xingbo Liu, New Mechanistic Insight into the Oxygen Reduction Reaction on Ruddlesden-Popper Cathodes for Intermediate-Temperature Solid Oxide Fuel Cells. Physical Chemistry Chemical Physics, 2016 DOI: 10.1039/C6CP00056H

Wenyuan Li, Bo Guan, Jianhua Yan, Nan Zhang, Xinxin Zhang, Xingbo Liu, Enhanced surface exchange activity and electrode performance of $\left(\mathrm{La}_{2-2 x} \mathrm{Sr}_{2 \chi}\right)\left(\mathrm{Ni}_{1-x} \mathrm{Mn}_{x}\right) \mathrm{O}_{4+\delta}$ cathode for intermediate temperature solid oxide fuel cells, Journal of Power Sources, doi:10.1016/j.jpowsour.2016.04.022 